\title{
Oral care product formulations, properties and challenges
}

Article

Accepted Version

Creative Commons: Attribution-Noncommercial-No Derivative Works 4.0

Aspinall, S. R., Parker, J. K. ORCID: https://orcid.org/00000003-4121-5481 and Khutoryanskiy, V. V. (2021) Oral care product formulations, properties and challenges. Colloids and Surfaces B: Biointerfaces, 200. 111567. ISSN 0927-7765 doi: https://doi.org/10.1016/j.colsurfb.2021.111567 Available at https://centaur.reading.ac.uk/95441/

It is advisable to refer to the publisher's version if you intend to cite from the work. See Guidance on citing.

Published version at: https://www.sciencedirect.com/science/article/pii/S0927776521000114

To link to this article DOI: http://dx.doi.org/10.1016/j.colsurfb.2021.111567

Publisher: Elsevier

All outputs in CentAUR are protected by Intellectual Property Rights law, including copyright law. Copyright and IPR is retained by the creators or other copyright holders. Terms and conditions for use of this material are defined in the End User Agreement.

\section{www.reading.ac.uk/centaur}

\section{CentAUR}

Central Archive at the University of Reading 
Reading's research outputs online 


\section{Oral care product formulations, properties and challenges}

Sam R. Aspinall ${ }^{1}$, Jane K. Parker ${ }^{2}$, Vitaliy V. Khutoryanskiy ${ }^{1 *}$

1. Department of Pharmacy, University of Reading, Whiteknights, Reading, UK

2. Department of Food and Nutritional Sciences, University of Reading, Whiteknights, Reading, UK

\section{Abbreviations:}

White spot lesions - WSL

Chlorhexidine - CHX

Carboxymethyl cellulose - CMC

Sodium lauryl sulfate - SLS

Cocamidopropyl betaine - CAPB

Sodium methyl cocoyl taurate - SMCT

Triclosan - TCS

Nanoparticles - NPs

\section{Abstract}

This review explores the physical, chemical and structural properties of key components of oral care products, whilst looking at the challenges which need to be overcome to continue to improve the efficacy of oral care, and improve dental health. Oral care has been an essential part of all populations and cultures around the world for thousands of years. To maintain good oral health, dental plaque causing bacteria and malodour must be controlled whilst also strengthening and protecting the teeth to prevent dental caries. Advanced modern formulations need to provide controlled and extended release of ingredients vital for dental health. With modern day products such as toothpastes and mouthwashes, it has never been easier to maintain good oral hygiene and health, yet the incidence of dental caries is still on the rise. The complex formulations of modern toothpastes and mouthwashes makes them one of the most sophisticated pharmaceutical products on the market today. The demands of the consumer coupled with the complexity of the oral cavity make it one of the most challenging development processes.

Keywords: Oral Care; Toothpaste; Formulations; Oral cavity; Active ingredients; Mucosal surfaces; mucoadhesion.

Correspondence should be addressed to Prof Vitaliy V. Khutoryanskiy, email:

v.khutoryanskiy@reading.ac.uk

Statistical summary: 16265 words, 8 figures/tables 


\section{Introduction}

Over the last 100 years, advances in oral care have improved the oral health of millions of people across the world. However, incidences of dental caries and oral diseases are on the rise due to the increase in availability of sugary foods as well as an increase in the consumption of acidic drinks [1]. The change in our diets has led to an increase in dental erosion and allows the oral microbial flora to thrive.

The diverse oral microbial flora is home to more than 700 types of bacteria species or phylotypes [2]. Of these, some of the bacteria present form sticky biofilms known as dental plaque which forms on the surface of teeth and around the gum line [3]. The removal of this plaque from the tooth's surface and the reduction of bacteria which produce acids capable of eroding enamel and mal odour is key to maintaining a healthy and fresh feeling mouth [4]. If teeth are not cared for properly then acid erosion and plaque staining will occur leading to cavities, tartar build up and sensitive teeth. More efficient ways to reduce dental decay and disease are needed [5]. To overcome these issues, extensive research of toothpaste and oral care products has been carried out leading to a welldeveloped understanding of how these products work and interact through chemical, mechanical and physical factors. The huge and ever-expanding market for oral care products has led to continued development and research of formulations and novel materials such as enzymes [6-7]. The ability to treat and prevent minor dental diseases such as gingivitis, oral thrush and bacterial causing throat infections, as well as better management of mouth ulcers and gingival (gums) healing after dental surgery, have made the maintenance of a good oral health care routine for millions easier. This paper will look at some of the key physical components of oral care products and how they are responsible for improving and maintaining oral health and how they make up the physical properties of the formulations.

\subsection{Oral Cavity}

While looking at oral care products, it is first important to understand the oral cavity. The anatomy of the oral cavity has been thoroughly investigated and a great deal of information is known [8]. As this is the case, this review will only briefly focus on the parts relevant to the subject. The oral mucosa itself is a moist membrane that is mainly composed of stratified squamous epithelium which overlays a connective tissue proper or a Lamina Propria [9]. The oral mucosa can be divided into three categories based on histology and their function within the oral cavity. Firstly, the masticatory mucosa is the keratinized mucosa that covers the hard palate and gingiva. The need for a stronger and more rigid masticatory mucosa is due to the abrasive and mechanical forces used during the masticatory processes [10]. Any damage to the masticatory mucosa increases the risk of infection from foreign bacteria and pathogens present in food and other objects that enter the mouth. In contrast, the lining mucosa is non-keratinized and covers a much larger percentage of the oral cavity than the other mucosa types. This non-keratinized mucosa can again be broken down into subcategorized tissues such as the labial mucosa which is located in the lining of the lips and buccal mucosa which is found in the lining of the cheeks and the floor of the mouth. The third type of oral mucosa is the specialized mucosa which covers the dorsum of the tongue. The dorsum of the tongue is a combination of both 
lining and masticatory mucosae which contains nerve endings for taste perception and sensory reception. These salivary glands secrete a slimy viscoelastic material known as saliva which is mainly composed of water and mucins [11]. This mucus has a variety of roles from helping to create a layer over the gingiva and oral cavity to protect against abrasions and pathogens as well as providing lubrication for masticatory processes [12-13]. Lingual papillae are small structures located on the surface of the tongue. These structures give the tongue a rough texture which aids in the consumption of food. There are four types of lingual papillae located on the tongue: filiform papillae are small cone shaped, keratinised papillae and the most numerous papillae that cover the dorsal surface and are responsible for the tongue's sensation of touch; fungiform papillae are covered by non-keratinised mucosa and are located at the front of the tongue and contain taste buds and temperature receptors; foliate papillae are short symmetrical vertical folds located on the sides at the rear of the tongue are covered by non-keratinised mucosa and contain taste buds; circumvallate papillae are round dome shaped structures at the back of the tongue near the tonsils which contain hundreds of taste buds and are surrounded by serous secretion from the Von Ebner's glands.

Teeth are critical in the digestive process as they are needed to chew and break down food that enters the mouth, reducing the surface area of the substance to aid swallowing and digestion and to reduce the risk of choking. They also play an important part in speech and communication through facial expressions [14]. Initially humans are born without teeth as mammals nurse their young, offering a selective advantage. Throughout their lifetime, humans will have two sets of teeth. The first set known as the deciduous teeth which develop around the age of 6 months and the second set known as the permanent teeth which form from roughly the age of 12 . The reason for this is that as the human body grows and develops the deciduous teeth do not continue to grow and need to be replaced by a larger set.

The average adult has four types of teeth in their oral cavity (Figure 1). The incisors are located at the front of the mouth and, as the name suggests, they are for biting/cutting into food during the first bite. The canines are the sharpest teeth in the mouth and are used for tearing food. Due to the premolars large surface area and flat biting surface, they are efficient at tearing and grinding food helping to turn solid bits of food into an easy-to-digest paste. 


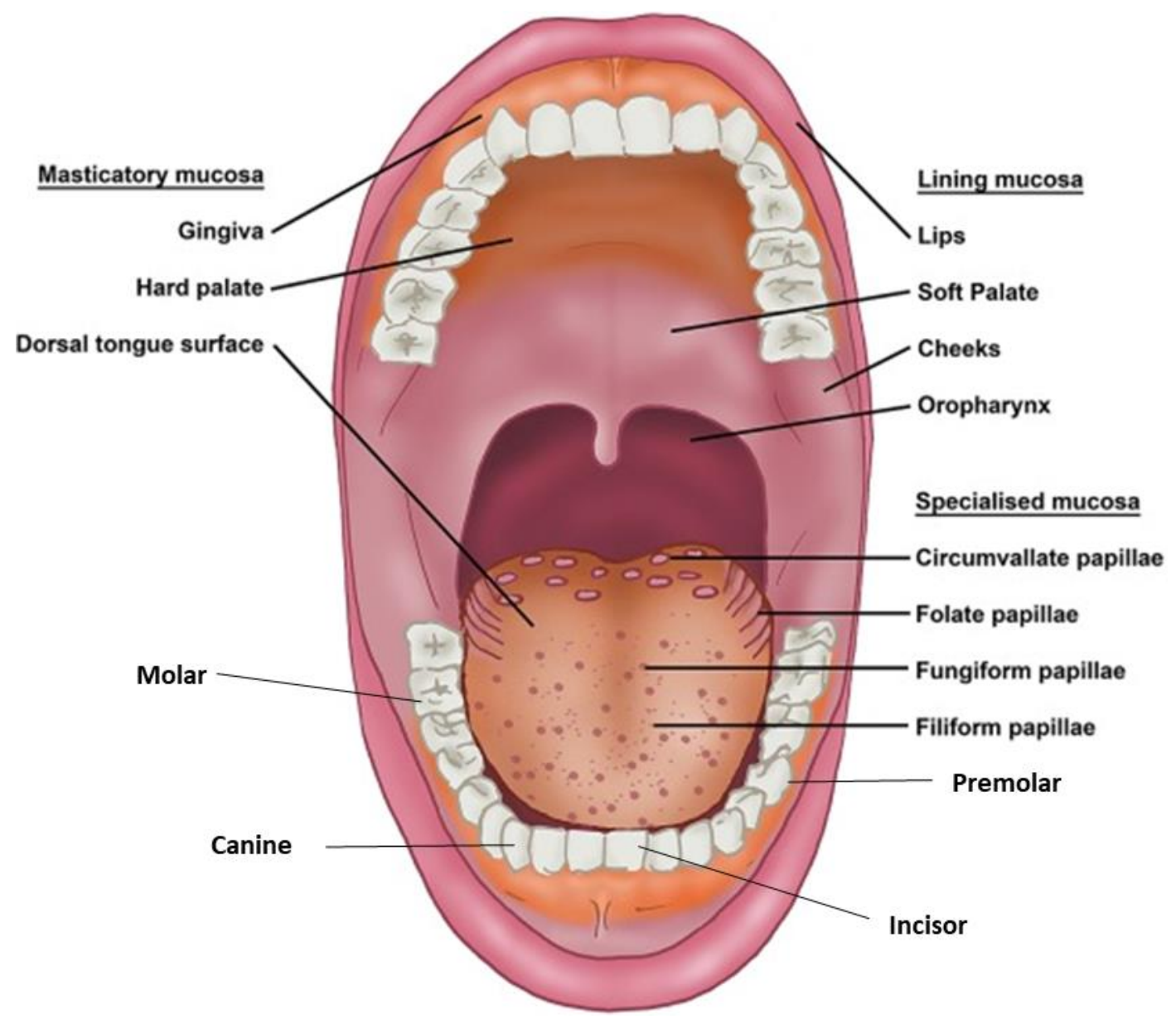

Figure 1. The positioning of mucosal surfaces and the 32 teeth present in an average adults' mouth. Reproduced from (Cook et al., 2017) [10] with permission from Elsevier.

The tooth is composed of three sections; the crown, neck and root (Figure 2). The root section of a tooth contains a complex network of nerves and blood vessels which stretch through the jawbone into the pulp chamber located in the centre of the tooth. The neck of the tooth is at the middle of the roots and crown surrounded by the gingiva. The crown of the tooth is the enamel covered top which is visible above the gingiva margin. Enamel is the highly mineralised white substance that protects the softer inside of the tooth. It is the hardest substance in the human body and has the highest percentage of minerals present although it is susceptible to erosion from acid and from a build-up of bacteria. To provide adequate protection to the soft dentin and nerves inside a tooth, the enamel layer can be as thick as $2 \mathrm{~mm}$ [15]. Enamel is made from $96 \%$ inorganic material including calcium hydroxyapatite $\left(\mathrm{Ca}_{5}\left(\mathrm{PO}_{4}\right)_{3}(\mathrm{OH})\right)[16-17]$. 


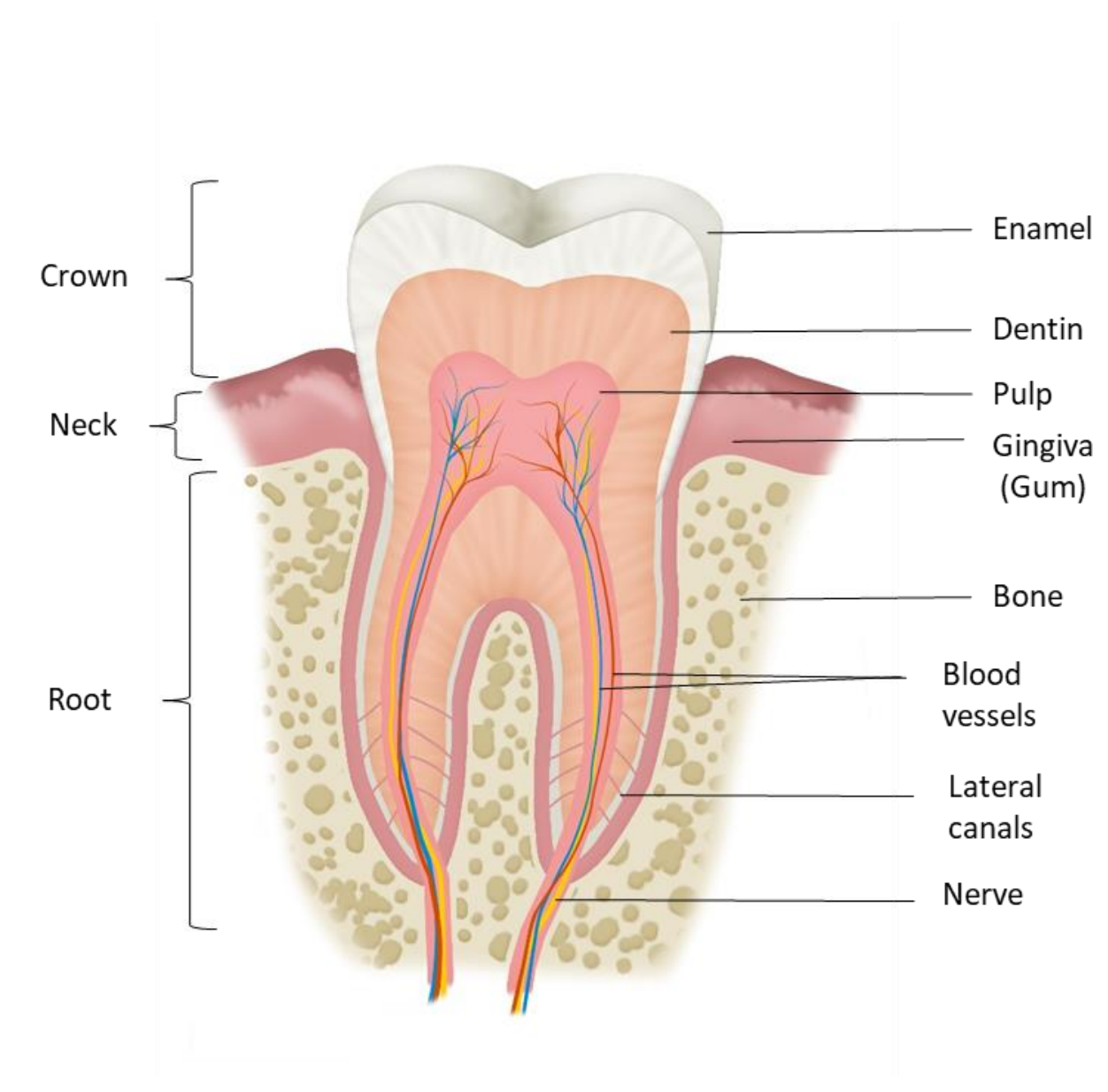

Figure 2. A cross-section of a tooth showing the key features and components

\subsection{Bacteria and plaque formation}

The oral cavity has a very diverse bacterial flora that inhabits it. Dewhirst et al have reported that over 700 different bacterial species or phylotypes have been discovered living within the oral cavity forming a bacterial biofilm coating all the surfaces present [18]. Most of the microorganisms that make up this oral biofilm play a role in protecting the body from outside stimulations [19]. However, this is not always effective and an imbalance of the microbial flora or invasion by a foreign body can occur leading to diseases and infections. Although most of the bacteria present pose no risk to the surrounding mucosal surfaces or the mineral rich teeth, some species have been linked to systemic diseases such as aspiration pneumonia, cardiovascular disease, some types of cancers and diseases of the oral cavity such as oral thrush, dental caries and gingivitis [19-24]. Continued research in this area has shown that the bacteria in our mouth play a much bigger role in maintaining our overall health and wellbeing, with the effects of foreign bacteria not just being localised to the oral cavity but having an effect on the whole body [19].

As the focus of this review is on oral care products such as toothpastes and mouth washes, details of how oral bacteria colonise the tooth's surface and how the acid they produce damages the enamel surface of teeth will be the main focus of this section. The most common bacteria associated with dental caries is Streptococci mutans (S. mutans) which is present in everyone's oral cavity from a very 
young age [25-26]. Dental caries as a whole are not caused solely by the bacteria, but by a series of processes. Food debris and mechanical damage also contribute to cavities, but acids produced by bacteria are the most common causes of dental plaque and dental caries [26].

Dental plaque, a soft sticky film that builds up on the tooth surface, particularly around the gum line, is produced via multiple steps (Figure 3). The first step involves the attachment of bacteria to the acquired pellicle. Immediately after the teeth have been cleaned, an acellular layer is formed when salivary glycoproteins, lipids, mucin, exoproducts (any exocellular product) and phosphoproteins form on the cleaned enamel surface [26]. In stage 2, as reported by Fachon-Kalweit et al. Streptococcus sanguinis (S. sanguinis) form weak, reversible van der Waals bonds, providing the initial foothold for the bacteria to start colonising the tooth surface [27]. If the bacteria are not removed, they are able to anchor themselves to the hydroxyapatite surface using pili (hair like appendages that are located on the surface of certain types of bacteria). In Stage 3, organisms that were not able to initially attach to the pellicle start to irreversibly adhere to the first layer of bacteria on the tooth's surface via adhesion-receptor interactions [28]. The bacteria that have bonded, start to replicate forming microcolonies. In stage 4, the early colonisers have now become well established. Due to this, the colony of bacteria now known as dental plaque, becomes increasingly complex as more oxygen is consumed by the ever-growing number of bacteria present [29-30]. The high demand for oxygen leads to anaerobic zones being created. The continued maturation of the bacteria eventually leads to a decrease in the rate at which cell division occurs as the demand for food needed for growth outpaces the supply and space on the oral surface becomes limited. Eventually, a pseudo steady-state climax community is formed [31]. By now, a thick layer of dental plaque is visible. In the final stage, the bonds holding these microorganisms to the tooth can be reversed by enzymes or mechanical forces, and the microorganisms are able to spread throughout the oral cavity and will begin the cycle again by colonising new surfaces as these biofilms are able to form on any surface inside the oral cavity [32].

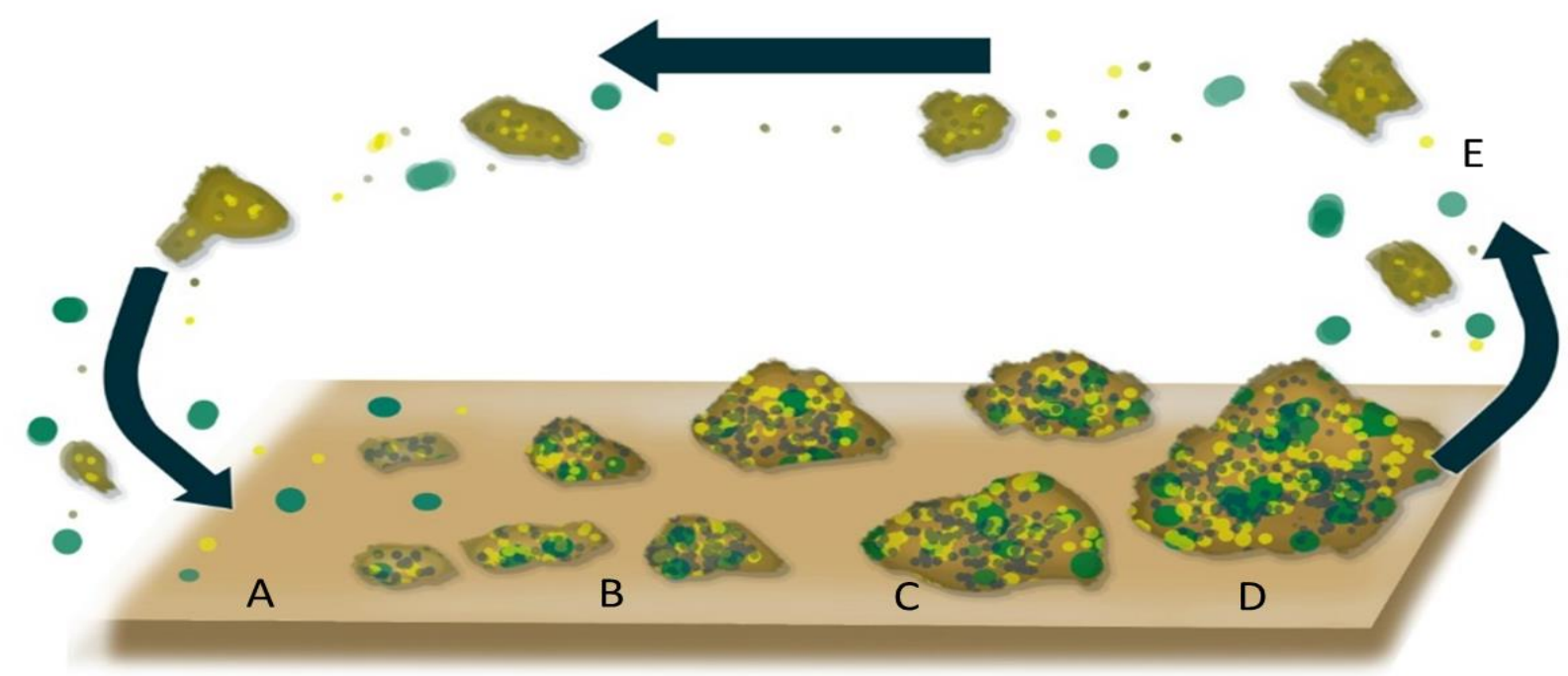

Figure 3. A) Attachment of bacteria to oral surface via reversible adhesion. B) Formation of weak covalent and ionic bonds by the bacteria to secure their position on the surface. C) Development of biofilm clusters as bacteria start to grow, divide and congregate with other bacteria. D) Biofilm in a 
pseudo steady-state. E) Bacteria and biofilm detach from surface and is dispersed beginning the cycle again.

\subsection{Tooth decay}

Tooth decay (also known as dental caries or cavities) is a progressive, multifactorial disease in which the surface structure of a tooth decays over time. This is caused by the irreversible solubilisation of hydroxyapatite by the acids that are produced by the bacteria during their metabolic processes. This is exacerbated by the increased intake of sugary foods, drinks and by sustained poor oral hygiene [33]. Although tooth decay is less prevalent than it was in previous decades due to better oral hygiene of the global population and the addition of fluoride compounds into most toothpaste formulations, our changing diets, habits and longer life expectancies mean that dental caries persist. The development of dental caries is not an overnight occurrence as the process of demineralizing and breaking down the enamel surface occurs throughout a person's lifetime [33-34].

In the initial stages of tooth decay, there are no symptoms other than the white spot lesions (WSL) which are observable on the enamel surface. These localised WSLs occur due to a subsurface enamel demineralization located on the smooth surfaces of the teeth [35-36]. These lesions occur where there is a prolonged exposure to plaque which has accumulated on the surface and has not been disturbed for long periods of time [37-38]. Exposure to the acids produced by the plaque bacteria leads to the demineralization and decalcification of the enamel surface. Demineralization of tooth enamel occurs at $\mathrm{pH} 5-6$ [39]. The critical $\mathrm{pH}$ is the $\mathrm{pH}$ at which the saliva and plaque fluid are not saturated with phosphate and calcium allowing hydroxyapatite in the enamel to dissolve [40]. A pH of 5.5 is considered the critical $\mathrm{pH}$ for enamel.

However, WSL are not only caused by demineralization. Fluorosis from excessive fluoride ingestion as teeth develop, enamel hypoplasia (a deficiency in the amount of enamel present on a tooth), hypomineralization (a softening and discolouration of the enamel) and hypomaturation (part of the medical condition Amelogenesis imperfecta which presents abnormal formations of the enamel) also cause lesions to develop [38]. The spots appear a different shade of white to the rest of the tooth surface due to decalcification and the newly formed porous enamel surface causing localised light to scatter differently due to the difference in the refractive index of enamel $(\mathrm{RI}=1.62)$ compared to the lesion ( $\mathrm{Rl}=1.33$ ) [41-42]. As this is a very early stage of tooth decay, the enamel can be re-mineralized with topical fluoride treatments and fluoride toothpastes.

In the second stage, the enamel starts to break down due to sustained demineralization. This enamel decay increases the risk of the tooth's surface breaking which will cause irreversible damage. During this stage, as the enamel layer is breached, dentin hypersensitivity starts to develop. If the enamel decay is not stopped and continued demineralization of the enamel occurs, the tooth could potentially break, and dentin decay will start to occur. Once this stage has been reached, the level of pain experienced by the person will intensify and sensitivity to stimuli will increase [43].

When enough phosphate and calcium minerals have been lost, the enamel will collapse and form a dental cavity. The cavity has a dark brown/black colour and increases with size the longer the tooth is left untreated and exposed to acid and bacteria. A dental filling or root canal surgery will need to be carried out to relieve the pain and discomfort whilst ensuring the integrity of the tooth is maintained and no more damage occurs. If the cavity is not treated, the pulp located in the centre of the tooth 
can become infected by bacteria present in the oral cavity causes pulpitis to develop. Micro-organisms that reach the dentin trigger an inflammatory response which if untreated can lead to persistent reoccurrence causing permanent loss of normal tissue and in turn reducing the ability for the cells and tissue to repair itself [44]. The colonisation of the root canals by bacteria causes blood vessels and nerves to start dying and exudate starts to form [45]. If the bacteria are not removed/killed, complications such as septicaemia, cardiovascular disease, shock, infections into the surrounding bones and tissue which can lead to brain abscesses and even death [43, 46-47]. The final stage of tooth decay is tooth loss. The damage done to the tooth has reached the stage where the tooth must be extracted.

Tooth decay is easily manageable with a regular cleaning routine. Using specific oral care products and routine dentist appointments are key to preventing damage, discolouration and disease from occurring in the oral cavity or treating any issues before they can evolve into problems. The strong composition of teeth and their high strength mean that teeth will be able to outlast their owners if properly maintained.

\section{Ingredients of oral care products and how they work}

Toothpastes are a paste or a gel that are used alongside a toothbrush to maintain and improve a person's oral health and aesthetics. Modern formulations are very complex and contain a large range of active ingredients to provide a thorough cleaning of the mouth without damaging the enamel surface or any of the gingiva. Modern toothpaste and oral care formulations contain active ingredients which actively fight cavities and gum disease, and inactive ingredients which provide stability and aesthetics to the formulation. The large number of ingredients which make up modern formulations must be able to remove plaque and bacteria from the mouth whilst also whitening teeth and leaving a fresh long-lasting flavour which leaves the user satisfied and improves confidence.

\subsection{Fluorides}

Addition of fluoride ions is a very effective way of controlling dental caries making fluorides a key active ingredient in modern toothpastes and some countries' water supplies [48-49]. The inclusion of fluoride containing compounds such as sodium fluoride, stannous fluoride and sodium monofluorophosphate has become commonplace in most toothpastes [50]. Due to its potentially toxic effects, fluoride concentration in toothpaste is generally low $(1000-1500 \mathrm{mg} / \mathrm{kg}$ ) [51]. Even though the concentration of fluoride in the toothpaste is low, it is enough to provide a therapeutic effect. However, if a large amount of toothpaste is ingested, it is still possible to get fluoride poisoning.

Research has shown that fluoride slows down the rate at which dental caries form by controlling the rate at which cavities develop [52]. The longer the fluoride ions are able to stay in the mouth without being washed away, the more they will be absorbed by the surface of the teeth. When the fluoride is on the surface, it has a topical effect. Plaque bacteria produce acids such as lactic, acetic and propionic acid from metabolic processes. These acids demineralise the enamel surface of the tooth leading to dental caries and dentin hypersensitivity [52]. As mentioned earlier, the structure of enamel is made up of calcium hydroxyapatite crystals [53].

As well as helping to re-mineralize teeth, there is evidence that fluorides influence the bacterial metabolism of dental plaque. Research by Marquis et al has shown that fluoride is able to 
act as an enzyme inhibitor or form metal-fluoride complexes which are able to lower the acid tolerance of the bacteria [54-55]

\subsection{Abrasives:}

Abrasives are one of the key ingredients in any modern toothpaste. Although they play a very active role in removing plaque and stains from the teeth and gingiva, they are considered an inactive ingredient in the formulation as they do not reduce the risk of cavities. Choice of suitable abrasives is important as they must be abrasive enough to remove plaque and bacteria from the tooth surface but not so abrasive that they cause any damage to the enamel [56-58]. They are typically an insoluble component of the toothpaste and were the key ingredient in the very first toothpastes. Commonly used abrasives include calcium carbonate, sodium bicarbonate, hydrated silica and dicalcium phosphate [59]. The surface of these abrasives is coarse but not so much that is would damage the enamel surface. The size of particles used as abrasives is a critical factor in determining their effectiveness. If the particles are too small, they will not be abrasive enough to remove stains and plaque from the enamel but if they are too large, they could cause unnecessary damage. As the particle size needs to fall within a specific range, the average particle size of abrasives is kept within a range of 4 to $12 \mu \mathrm{m}$ [60]. Additionally, abrasion caused by the type of toothbrush used and the firmness of the bristles also plays a large role in oral care and, if incorrectly used, enamel and gum damage although this is beyond the scope of this review and will only briefly be mentioned. Again as with abrasives in toothpaste, consideration must be made into what materials can be used to make the bristles as these will come into contact with all surfaces in the oral cavity.

Abrasives however can be a double-edged sword when it comes to protecting tooth enamel. Studies have shown that if the tooth enamel is already eroded, then abrasion of the damaged surface can lead to loss of tooth volume as well as softening the surface [61-62]. Enamel has a Mohs hardness of 5 meaning that any mineral or abrasive used to clean the enamel surface must be lower than this value to prevent damage and erosion to the surface. Calcium carbonate has a Mohs hardness of 3 making it an ideal abrasive for removing plaque and polishing the enamel surface [63].

For the abrasives to work, the plaque, stain or bacteria must come into contact with the abrasive. The contact generates tensile and shear stresses which in turn is able to break the bonds between the substrate and the surface. When this bond is broken, the substrate particles are removed from the surface and enter the toothpaste solution. The substrate then leaves the mouth when the solution is spat out. However, the roughness of the intraoral surfaces has been shown to affect the retention of plaque bacteria [64]. As most of the microorganisms that grow in the oral cavity can only survive by adhering to non-shedding surfaces, teeth make the optimum location for these organisms to thrive. The roughness of teeth due to their erosion over time from abrasion and acid damage helps bacteria to adhere to the surface better. By increasing the roughness of a tooth's surface, microirregularities start appear. Bacteria that attaches to these surface irregularities are protected from salivary flow, masticatory function and potentially brushing allowing them to form stronger attachments to the enamel surface. There are plenty of studies that have shown a correlation between the roughness of the enamel surface and the increase in bacterial adhesion [64-66]. Bollen et al showed that if the roughness of the surface has a $R_{a}$ (surface roughness average) value above $0.2 \mu \mathrm{m}$, an increase in bacterial colonization on the surface can be observed [64]. This indicated that if the 
surface of enamel and the gingiva can be kept smooth, the adhesion of plaque bacteria to the surfaces should decrease due to its lower surface free energy and lower roughness. An in vivo study by Quieyen et al showed that a high substratum surface free energy coupled with the rough surface of the teeth facilitates the growth of supragingival bacteria [65].

By increasing the surface roughness, the surface area of the tooth is increased and the total surface energy increases. However, although bacteria is able to bind to the enamel surface easier, a rougher surface favours the growth of plaque bacteria more than surface free energy as the protection provided from salivary, mechanical and mastectomy processes reduces the chances of the bacteria being dislodged from the surface.

\subsection{Whitening/bleaching agents}

All toothpastes to some extent help whiten teeth by removing stains from the enamel surface, but the product specifically designed to whiten teeth was first formulated and marketed in the 1980s. Since then, the rapid growth and development of these formulae and their ever-increasing demand and availability has led to these toothpastes taking up a large share of the market. As abrasives have been looked at already in this paper, chemical and alternative agents used in whitening toothpaste will be the focus of this section.

The colour of teeth is a strongly debated topic as there is no single shade of white teeth. Due to factors such as diet, genetics and habits such as smoking, teeth will become stained over time. Extrinsic stains occur on the outer layer of the tooth due to depressions and tiny groves in the enamels structure [67]. These defects retain stain-producing substances like coffee and red wine and allow them to bind to the surface. Even oral care products which contain fluorides, chlorhexidine (CHX) a commonly used antibacterial or delmopinol a surface-active anti-plaque agent, can cause staining when used above the recommended levels [68]. Claydon et al showed that using rinses containing 0.1$0.2 \%$ delmopinol had an increase in staining particularly with the $0.2 \%$ solutions and Yates et al have demonstrated that a $1 \% \mathrm{CHX}$ toothpaste can cause tooth staining over time [69-70].

Intrinsic staining occurs deeper where the thickness of the hard tissue or the structural composition of the tooth is changed during its development [68]. There are multiple causes for intrinsic staining such as use of tetracycline antibiotics by the mother during pregnancy or a person as an infant, dentinogenesis imperfecta which causes grey purple and amber discolouration and dental trauma [69-70].

If teeth are not cared for properly, tooth decay can alter the colour and shape of the enamel. The acids produced by plaque bacteria and ingested in our diets can lead to teeth turning blue or yellow in the early stages. This change in colour is repairable in the early stages but during the later stages, active carious lesions and arrested caries turn brown or black. Once this damage to the tooth structure and the dentin has occurred, the tooth will either require removal or dental surgery to correct [71-72].

Ingredients described in literature for removing stains include chemicals such as peroxides, citrates and pyrophosphates as well as certain enzymes and surfactants [73]. A key challenge that must be overcome when applying these ingredients to teeth via toothpaste is the short contact time 
of the formulation and the structure of the surface [74-75]. Despite this issue, oxidative chemicals such as hydrogen peroxide have been shown in vitro to lighten teeth and reduce the tooth yellowness compared to other formulations that did not contain a bleaching agent [76]. The peroxide can penetrate the enamel where it is able to bleach or decolourise the stains through an oxidation reaction [77]. Currently, research using the enzyme bromelain extracted from pineapples and papain extracted from papaya was compared to commercially available toothpaste [78]. The research showed that the formulation containing the enzymes was more effective in removing the stains compared to the control [79-81].

\subsection{Mucoadhesives and other binding agents}

The oral mucosa is the mucous membranes responsible for producing mucus and preventing the oral cavity from drying out. Due to the large surface area covered by this membrane inside the cavity, the use of mucoadhesives to enhance the retention of oral care formulations is a common if not overly reported practice. Mucoadhesion can be defined as the attractive interactions between a polymeric material and the mucus that covers the mucosal tissues or the mucous membrane [81]. The theories and mechanisms behind mucoadhesion are beyond the scope of this paper and have been reviewed in detail by multiple researchers [10,83-88]. Good mucoadhesive compounds are those that possess charged groups or can form hydrogen bonds with the mucin or mucosal surfaces [83].

Anionic polymers such as carbopols, carboxymethylcellulose (CMC), polyacrylic acid and polycarbophil can form hydrogen bonds between the carboxylic acid and hydroxyl groups of the mucus glycoprotein [89]. Carbopols, CMC and xanthan gum are commonly used thickening agents in oral care products and cosmetics. Non-ionic polymers generally have poorer mucoadhesive performance than polyelectrolytes [90]. Interactions between the non-ionic polymer and mucin are very weak.

Two of the most common binding/thickening agents used in oral care products, pharmaceuticals and foods are carboxymethyl cellulose (CMC, Figure 4a) and xanthan gum. CMC is an anionic polysaccharide commonly found in oral care formulations. It is synthesised by an alkali-catalysed reaction where alkali cellulose is reacted with sodium monochloroacetate [91]. It is used as a binder to stop the liquid ingredients from separating out from the powdered ingredients. The functional properties of $C M C$ can be altered depending on the degree of substitution of the hydroxyl group and the degree of of polymerisation [9]. Because of this flexibility, CMC has good mucoadhesive properties in solid, liquid and gel forms [10]. It is added to many different products as a viscosity modifier helping to increase the thickness [92]. The viscosity of $\mathrm{CMC}$ changes depending on the $\mathrm{pH}$ of the solution. When the $\mathrm{pH}$ values are between $6.5-9$, its carboxylic groups are mostly ionised, which results in higher viscosity. Generally, toothpastes and oral care products are neutral or slightly acidic in terms of $\mathrm{pH}$ although whitening and bleaching formulations contain acids which make them slightly more acidic.

Carbopols (Figure 4b) or polycarbophiles are polymers of acrylic acid that are weakly cross-linked with polyalkenyl ethers or divinylglycol [93]. Their mucoadhesive properties come from the carboxylic groups and their ability to form strong hydrogen bonds between the polymer and the oligosaccharide chains present in the mucin. Carbopol polymers/carbomers are high molecular weight polyacrylic 
acids used in cosmetics and oral care products as thickening agents and binders. They are typically added to liquids, gels or pastes to change the rheological properties.

Cationic polymers like chitosan (Figure 4c) have been reported as very good mucoadhesives. Chitosan is a widely used non-toxic polysaccharide which is composed of N-acetyl-D-glucosamine and Dglucosamine units linked by $\beta$-(1-4) D-glucosamine bonds in a random distribution [94]. Chitosan like other cationic polymers can electrostatically interact with the negatively charged mucin due to the presence of sialic acid and is also able to form hydrogen bonds with mucin [95]. The low cost and relative abundance of chitosan, and its ability to form strong bonds with mucin make it one of the best mucoadhesive compounds available. However as the main source of chitosan is from crustaceans, this reduces its commercial viability as consumers with allergies to crustaceans would not be able to use this product unless the chitosan came from a different source such as fungi.

Gantrez ${ }^{\circledR}$ is another polymer which has been shown to have strong mucoadhesive properties. It is an alternating copolymer of methyl vinyl ether and maleic anhydride (Figure 4d). When Gantrez ${ }^{\circledR}$ is dissolved in water it results in hydrolysis of its anhydride cycles and liberation of carboxylic groups. Although not typically used in oral care products, Gantrez AN-169 is used in denture adhesives. Work by Kockisch et al demonstrated that polymeric microspheres made from Gantrez ${ }^{\circledR}$ were able to better retain on mucosal tissue with artificial saliva than those that were made from poly(acrylic acid)s [96].

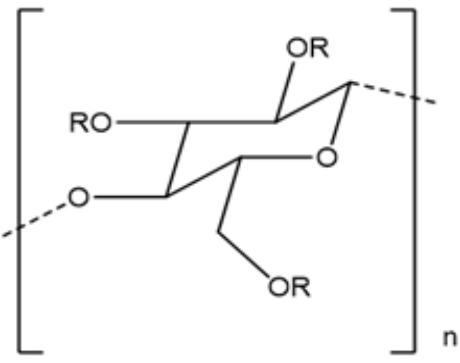

$\mathrm{R}=\mathrm{H}$ or $\mathrm{CH}_{2} \mathrm{CO}_{2} \mathrm{H}$

a

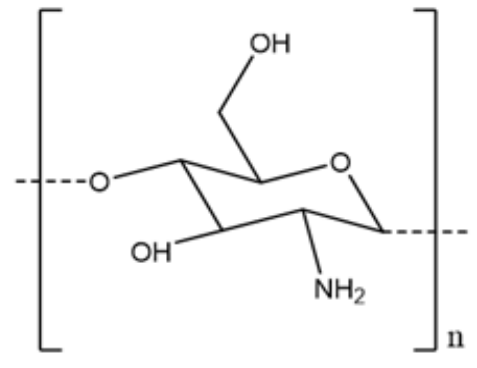

c

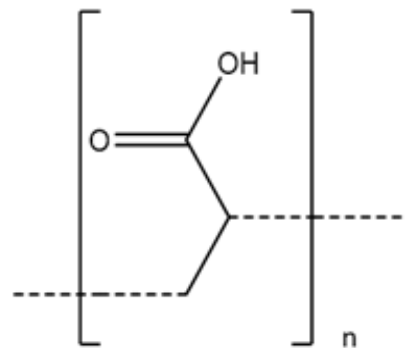

b

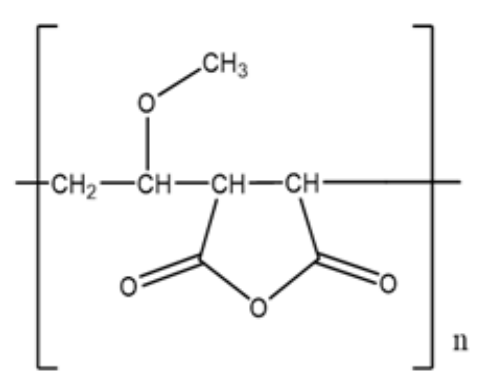

d

Figure 4. (a) Structure of carboxymethyl cellulose $(C M C)$; (b) structure of polyacrylate $\left(\right.$ Carbopol $\left.^{\circledR}\right)$; (c) structure of chitosan; (d) structure of Gantrez ${ }^{\circledR}$ 
Xanthan gum is an extracellular heteropolysaccharide, which is produced by the fermentation of glucose, sucrose or lactose by Gram-negative bacterium Xanthomonas campestris [97]. The anionic polysaccharide is made up of repeating units of glucose, glucuronic acid and mannose. Much like CMC, xanthan gum is used as a thickening and stabilising agent making it an excellent choice for binding and keeping the formulations uniform. Xanthan gum has shown mixed results in the past with regards to its mucoadhesive strength with some studies showing it had poor mucoadhesion to buccal surfaces [98-99], with others reporting it had good mucoadhesion [99-100].

Over the last few decades there were numerous attempts in the design of polymers and other materials with enhanced mucoadhesive properties. This enhancement could be achieved through functionalisation of these materials with specific groups capable of forming covalent linkages with mucosal surfaces under physiological conditions. One of the most prominent examples of polymers with chemically enhanced mucoadhesive properties is thiomers. Thiomers are hydrophilic polymers which contain thiol bearing functional groups on their side chains [84, 101]. These polymers form covalent bonds via a disulphide bridge with cysteine-rich subdomains of mucus glycoproteins [102]. These covalent bonds provide a stronger link between the polymer and the mucin meaning the polymer has enhanced mucoadhesive properties over other mucoadhesive compounds [89]. Some thiolated polymers have already been commercialised for pharmaceutical applications, for example, thiolated chitosan has been used in the design of eye drop product called Lacrimera with improved retention on ocular surfaces [103]. In addition to thiolation, several other strategies for functionalisation of polymers to enhance their mucoadhesive characteristics have also been recently explored. These includes conjugation of mucoadhesive polymers with acryloyl, methacryloyl, boronate, maleimide, catechol and $\mathrm{N}$-hydroxy(sulfo)succinimide ester groups. The progress in the synthesis of polymers with enhanced mucoadhesive properties has recently been reviewed by Brannigan and Khutoryanskiy [104].

By adding mucoadhesive polymers to mouthwashes, gels and pastes, the retention of the active ingredients in the mouth will be increased along with the stability of the formulation helping to increase shelf life. By increasing the amount of time the active ingredients are in the oral cavity, their therapeutic effect can be sustained for longer. An increased retention will allow compounds such as fluorides and flavours which are usually washed away quickly after brushing to be retained for an increased amount of time.

\subsection{Flavour oils}

Several essential oils (EO) which exhibit antibacterial and antiplaque properties and have pleasant fresh tastes are used in washes and rinses. Thymol, menthol, eucalyptol and methyl salicylate are major components of the natural plant extracts from thyme, mint, eucalyptus and American wintergreen (Figure 5). US patent 8273385 B1 describes some formulations of Listerine ${ }^{\circledR}$ with a blend of EO in their products to provide taste and to act as antibacterial agents [105]. The use of EO as antibacterial and antifungal agents is well established in research. Although the use of EO as antibacterial agents is well known, the mechanism behind the antibacterial action is complex and was not fully understood until the mid-1980s. 


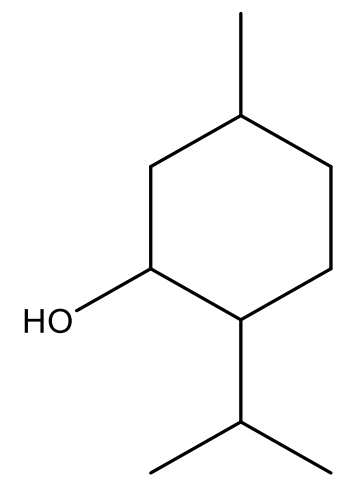

Menthol

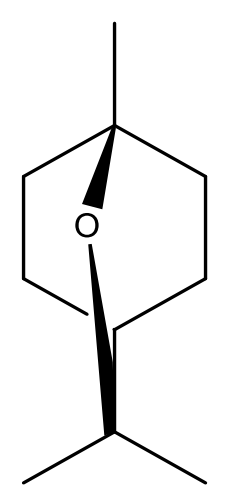

Eucalyptol

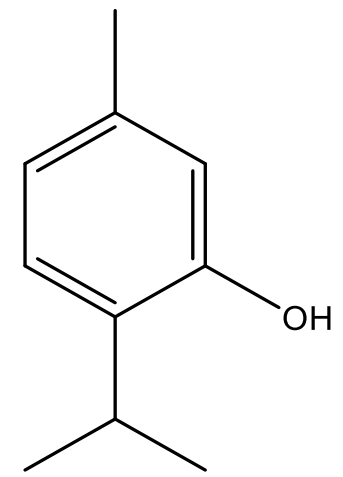

Thymol

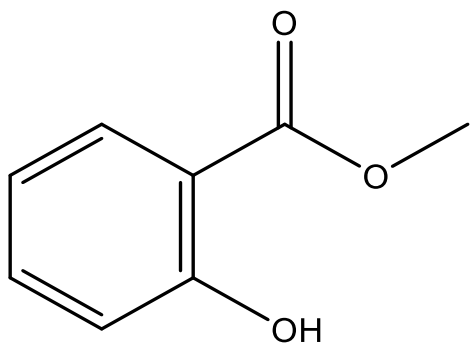

Methyl Salicylate

Figure 5. Structures of commonly used EO in oral care formulations

Continued research on these compounds has shown that they are effective antibacterial/antifungal agents when used individually and when combined with conventional antibiotics. A study carried out by Thaweboon and Thaweboon (2011) using an EO-containing mouth rinse used twice a day over a two-week period showed that mouth rinse containing EO can have a significant effect on lowering the number of volatile sulphur compound producing bacteria on the tongue helping to control oral malodour [106]. An in vivo study by Fine et al looked at the interproximal antibacterial activity of EO containing mouth rinse as they can easily reach the areas situated between adjoining teeth [107]. They used 34 volunteers who after brushing their teeth use a mouthwash which was either EO or saline solution for negative control. Five minutes after using the mouth rinse, interproximal plaque samples were collected using paper points. They recorded that 5 minutes after a single EO mouthwash application, there was a decrease of $44 \%$ in bacterial viability observed in the interproximal spaces with respect to the negative control [107]. Research has shown that although bacteria can become resistant to EO, this is very unlikely and has offered a promising line of research for antibiotics of the future [108-109].

Thymol, the major component of thyme, has been used in oral care formulations for decades. Thymol is a well-known antimicrobial agent and has been shown to induce a decline in intracellular adenosine triphosphate (ATP) in S. sobrinus due to leakage via membrane perforation [110-111]. In the case of $P$. gingivalis, thymol may inhibit ATP-generating pathways causing processes that require ATP to cease [110]. Additionally, thymol exhibits strong antifungal properties due to its lipophilic nature. This enables it to interact with the cell membrane of fungus cells, which in turn increases the membranes permeability. Macromolecules inside the cell are then lost due to the altered permeability of the cell wall [112-113].

\subsection{Desensitisers:}

Dentin hypersensitivity is an increasing clinical problem which causes a short sharp pain when exposed dentin is subjected to a stimulus [114]. The stimulus can be thermal, mechanical, electrical, chemical and a reaction to hypertonic solutions [115-116]. Although the pain only last for a short duration, immense discomfort when eating and drinking can impact on quality of life. There are a variety of causes of dentin hypersensitivity ranging from age, dietary, trauma and damage to teeth (Table 1). The leading causes of dentin hypersensitivity however is gingival recession, where the dentin and root surface are exposed with enamel erosion exposing the nerves and dentin. The enamel 
erosion is caused by acids produced by bacteria or from diet and mechanical erosion from improper cleaning of the teeth or from environmental factors. The discovery of desensitising agents which can be incorporated into toothpaste formulations is a key advancement in the oral care fields providing relief for millions.

Table 1. Common causes of sensitive teeth.

\begin{tabular}{|c|c|}
\hline Cracked tooth & $\begin{array}{l}\text { Teeth crack due to a variety of reasons. Damage from injuries, biting down on hard } \\
\text { foods and teeth grinding can cause cracks and chips to appear exposing nerves and } \\
\text { dentin leading to sensitivity. Age also plays a factor and sudden changes in temperature } \\
\text { can also cause cracks to form. }\end{array}$ \\
\hline $\begin{array}{c}\text { Dental } \\
\text { treatment }\end{array}$ & $\begin{array}{l}\text { Deep fillings can get close to the nerve endings and cause sensitivity and irritation } \\
\text { although overtime this can heal. A poor crown placement can alter a person's natural } \\
\text { bite causing sensitivity to occur. Additionally, if there is decay in the pulp under the } \\
\text { crown, pressure exerted on the tooth will cause pain. Tooth cleaning can lead to } \\
\text { sensitivity as areas that were covered by tartar and are not covered by enamel will } \\
\text { become exposed. }\end{array}$ \\
\hline Dental decay & $\begin{array}{l}\text { As dental decay causes the enamel surface to recede, exposing dentin tubules which } \\
\text { are connected to nerves inside the tooth. Bacteria, acidic food and drinks can enter } \\
\text { these tubes causing pain. Temperature changes from hot and cold food and beverages } \\
\text { can also cause pain and discomfort. }\end{array}$ \\
\hline Gum disease & $\begin{array}{l}\text { Inflamed mucosal tissue can lead to sensitivity as supporting ligaments can recede and } \\
\text { expose the tooth's root. As there is no enamel covering the root of the tooth, dentin, } \\
\text { pulp and nerves can be exposed leading to sensitivity and pain. }\end{array}$ \\
\hline $\begin{array}{c}\text { Tooth } \\
\text { whitening }\end{array}$ & $\begin{array}{l}\text { Oxygenating bleaches that are used to remove debris from within and on the tooth's } \\
\text { structure are able to also remove the plugs in the dentinal tubules. The fluid inside } \\
\text { these tubules moves away from the pulp down a concentration gradient. The } \\
\text { movement of this fluid causes sensitivity. }\end{array}$ \\
\hline $\begin{array}{l}\text { Thinned } \\
\text { enamel }\end{array}$ & $\begin{array}{l}\text { The erosion of enamel by acids and mechanical damage causes areas of dentin to be } \\
\text { exposed. Irritation by cold, hot or acidic substances leads to pain and sensitivity. }\end{array}$ \\
\hline $\begin{array}{l}\text { Poor oral } \\
\text { hygiene }\end{array}$ & $\begin{array}{l}\text { Poor oral hygiene leads to a build-up of bacteria on the tooth. The acids excreted by the } \\
\text { bacteria cause erosion to the enamel surface. As erosion occurs, dentine and pulp are } \\
\text { exposed. Irritation caused to the dentin and pulp lead to pain and sensitivity. Bacteria } \\
\text { can also cause the mucosal surface protecting the root to become inflamed causing } \\
\text { gum disease to develop. }\end{array}$ \\
\hline
\end{tabular}

The most popular theory as to what causes the dentin hypersensitivity pain was proposed by Brannstrom [117]. This hydrodynamic theory suggests that dentin hypersensitivity is caused by the movement of fluid inside the hollow dentinal tubules that run through the dentin in response to a 
stimulus [117-118]. The flow of the fluid inside the dentinal tubules leads to mechanical deformation which subsequently activates the nociceptor sending a threat signal to the brain [119].

The innervation theory suggest nerve endings can penetrate the dentine up to the detinoenamel junction, meaning that mechanical stimulation of these nerves will lead to an action potential $[114,120]$. As the odontoblast which are found in the outer surface of dental pulp are responsible for producing dentine, it was speculated that these cells were related to the cause of dentin hypersensitivity. The odontoblast receptor theory suggests that odontoblast themselves act as receptors and send the signal to a nerve terminal; however, studies have shown that the odontoblasts are matrix forming cells and are not excitable cells [114].

A wide variety of products have been developed to treat and manage dentin hypersensitivity with most of them being designed for home use. The products mainly come in the form of toothpastes and are designed to desensitize the exposed nerves or cover the exposed dentinal tubules with an impermeable substance [121]. Charig et al described a formulation that can desensitise the tooth and produce a layer of amorphous calcium phosphate on the surface of the dentin [122]. Then with the addition of fluoride, the calcium phosphate can reform as hydroxyapatite forming a complex which has a similar composition to the original tooth mineral [122].

Potassium and strontium salts are used as a nerve desensitising agents with the addition of eugenol or clove bud oil as enhancers [123-124]. Formulas which use these salts have been described in US patent US 8652445 B2 [123] and German patent WO 1999003445 A2 [124]. The salts can enter the dental tubules and reach the nerves. Once the potassium or strontium ions reach the nerves, they can decrease the excitability of the dental nerves by altering their membrane potential. However, even though potassium salts are often used as a desensitising agent in toothpaste, the effectiveness of them is still debated with some sources reporting the affect is minimal while others report a significant reduction in sensitivity [125-130].

\subsection{Surfactants}

Surfactants play a key role in modern formulations and as such, this section will look at surfactant types and focus on the most commonly used surfactants in the oral care industry. They are responsible for the foaming action of the toothpaste which aids the intraoral dispersion of the formulation allowing fluoride compounds to come into contact with teeth for as long as possible, the removal of debris, biofilms and plaque from the surface of the teeth and the micellization of flavour compounds and organic molecules such as triclosan [131]. To create a formulation which can reach all parts of the mouth, the right amount of surfactant must be used. Insufficient quantity of surfactant in the formulation results in less foam generated, which will not be enough to cover all of the teeth and mucosal surfaces, lowering the effectiveness of the product. Too much of surfactant present in the formulation would leave the consumer with an unpleasant experience and potentially cause irritation.

A combination of surfactants is used in any given formulation to balance out the properties of each compound used. Some surfactants such as sodium dodecyl sulfate used in high concentrations causes irritation to the soft oral tissue and cocamidopropyl betaine (Figure 6) has a bitter taste. A combination of both surfactants is able to balance out the negative effects and still provide an effective foaming system for the dentifrices [132]. 


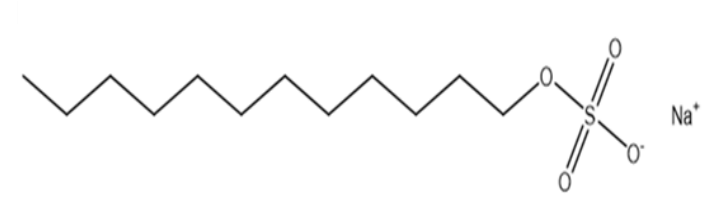

a

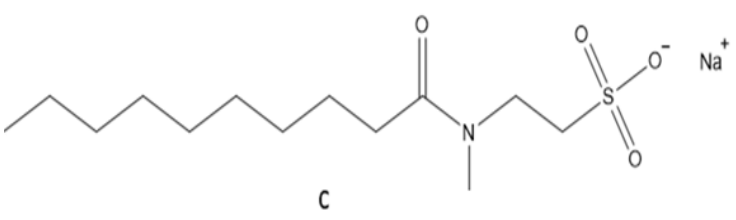

C

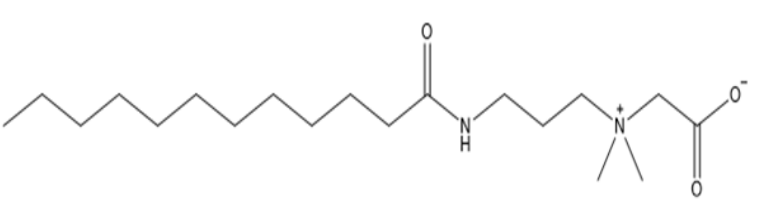

b

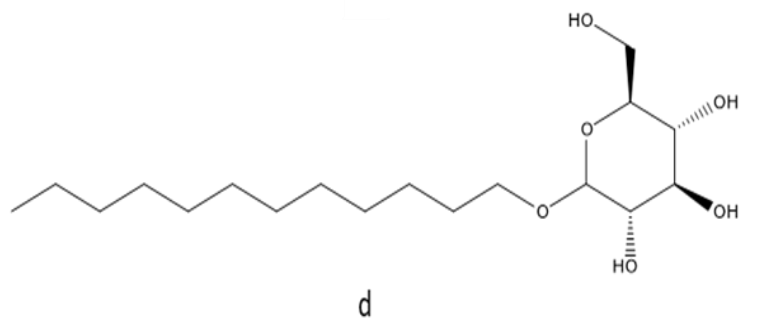

Figure 6. Common surfactants used in oral care formulations: (a) Sodium dodecyl sulfate (SDS or SLS); (b) Cocamidopropyl betaine (CAPB); (c) Sodium methyl cocyl taurate (SMCT); (d) Lauryl glucoside

Sodium dodecyl sulfate (also known as sodium lauryl sulfate (SLS)) is the most commonly used anionic surfactant in dentifrices and in the cosmetic industry. As well as being used as a surfactant, SLS has been shown to exhibit antimicrobial and plaque inhibitory properties [133]. The antimicrobial ability of SLS is due to its ability to penetrate through porous bacterial cell walls. Thereafter, interactions with the cell membrane lead to an increase in cell permeability causing leakage of intracellular components and cell lysis [133-134]. A study conducted by Landa et al found that the adhesion of S. mutans HG 985 could be reversed with a $4 \%(w / v)$ SLS solution [135].

Another surfactant, cocamidopropyl betaine (tego betain, CAPB) is an amphoteric material which produces a moderate amount of foam compared to other commonly used surface-active compounds. As it is a balanced amphoteric surfactant, it is less irritating to the mucus membrane than other detergents [136]. CAPB is a fatty acid amine that originates from coconut oil which is used as an amphoteric surfactant in oral care and cosmetic products. Because of its plant based origin, it is considered a natural ingredient so is used as a surfactant in products marketed as all natural. As CAPB is considered less irritating than other surfactants, it is used in sensitive and children's toothpaste.

Sodium methyl cocoyl taurate (SMCT) is a mild surfactant which is used as an alternative to SLS as it has less irritating characteristics. SMCT is usually used in combination with CAPB to reduce the bitterness whilst maintaining a low level of foaming [129].

Lauryl glucoside is considered more of a green alternative compared to other surfactants like SLS as, like CAPB, it is derived from coconuts allowing its production to be made sustainable. As it is nonirritating and it does not dry out skin and mucosal surfaces like sulfate containing surfactants, it is used in formulations designed for people with sensitive oral mucosa.

Although surfactants are very beneficial and help providing a better coating, the irritant nature of some of them and the potential damage done to the environment, has led to the development of surfactant free toothpaste [132]. Use of these surfactant-free formulations does not provide the benefits derived from the foaming properties and limits their reach within the oral cavity, diminishing the pleasant clean mouthfeel which accompanies surfactant toothpastes. 


\subsection{Mouthwash/mouth rinse:}

When looking at oral care products, one group of products which have seen particular growth and development in the last few decades are mouthwashes and rinses. A mouthwash or rinse is a nonsterile aqueous solution, which is mainly used for its antiseptic and freshening properties [137]. Most of these products have multiple functions such as reducing the amount of oral bacteria and food particles present in the oral cavity, neutralising acids produced by plaque bacteria and temporarily freshening the user's breath leaving a pleasant aftertaste. Mouthwashes are not designed to be used by themselves but developed as a part of an oral hygiene routine. Even though they have antiseptic and cleaning properties, they are not able to mechanically or physically remove plaque from the enamel and gingival surfaces.

The timing of mouthwash use after brushing is also an important factor in the effectiveness of the rinse and the toothpaste. Multiple studies have shown that rinsing using a mouthwash immediately after brushing with a fluoride toothpaste will reduce the amount of salivary fluoride available in the oral cavity, reducing the effectiveness of the remineralisation [138-140].

Ethanol is one of the main active ingredients in the majority of mouthwashes on the market as it is a food safe, cheap and readily available antiseptic. Some products even have ethanol concentrations as high as $27 \%$ [141]. The use of such high concentrations of ethanol in these products will cause irritation to the oral cavity and dryness. It has also been noted, that although mouthwashes leave a pleasant taste and fresh odour after use, the drying nature of the alcohol can cause an increase in xerostomia (dry mouth) [142]. Studies have shown that the use of ethanol in mouthwashes and rinses may cause oral cancer although this is beyond the subject matter of this review [143-144]. To overcome these issues and still provide the same quality of cleaning, alcohol-free mouthwashes have been developed. Alcohol-free mouthwashes are becoming increasingly popular as unlike the alcohol containing washes, there is no or very little irritation or dryness when used. This benefits people who suffer from sensitive gingiva, xerostomia or medical conditions. Instead of using ethanol, a blend of essential oils, ionic and non-ionic surfactants and flavour oils are used maintaining the effective as washes and rinses that contain alcohol [145-147].

\section{Physical Characteristics of Oral Care products}

Oral care products available on today's market have a wide range of physical characteristics, from their rheological properties, textures and appearances. All these characteristics are supposed to provide a pleasant experience for the consumer and make the storage of toothpaste inside tubes easier. Toothpastes have interesting rheological properties due to the complex nature of their formulation. This section looks at a few of these characteristics as well as exploring the pharmacokinetics of some of the active ingredients.

\subsection{Rheology, retention \& texture}

The texture, viscosity and the flow of an oral care product play a very large role in their development and production, especially that of toothpaste. A toothpaste that does not flow when squeezed from a tube as it is too thick, or one that falls off a toothbrush as it is too runny will affect customer satisfaction and drive consumers towards competitors' products [148-149]. Because of 
these challenges and the consumer's demands, the rheology of toothpaste has been extensively researched. The combination of dense ingredients and binders suspended in water and humectants gives rise to the interesting rheological properties of toothpastes. Modern toothpastes typically come in the form of a gel or paste. A gel is a semisolid system in which short range physical bonding interactions form a network structure that is able to immobilize the liquid contained in the gel [150151]. This gives the gel its semi-solid properties. A gel can additionally be described as a diluted system that exhibits no flow when it is in the steady-state [152]. Gels used in the oral care industry tend to be less abrasive than pastes and when spilt or dropped they produce a slightly smaller splatter. Pastes are slightly thicker in texture than gels and when applied to a surface, go on thicker. It is also important to note that the abrasives are not just added for the mechanical cleaning of the teeth, but also as a way of improving the rheology of the toothpaste. The abrasives are able to increase the shear-thinning and shorten the thixotropy of the toothpaste [153-154]. Toothpaste and oral care products generally follow the same formulas. Although there may be subtle changes in the ingredients used or the processes carried out to produce the product, the rheology of the formulations will be slightly different. Although the rheological profiles are similar, the use of different ingredients means that each toothpaste will have a unique microstructures from each other giving each paste a marked difference in rheology. Work by Zhiwei et al found that differences in the microscopic structure of toothpaste are likely responsible for the differences in their rheological properties when measured in both steady and dynamic states [155]. Their work concluded that toothpastes that are composed of fine particle dispersions forming well connected network structures have different rheological properties to those that have a poor network [155].

Toothpastes are classed as a Bingham plastic in which at low stresses, such as resting inside a tube of toothpaste with no external forces being applied, it will start to flow returning to its resting state (Figure 7). This differs slightly from Newtonian fluids in that a finite shear stress is required to initiate the flow [156-157]. Because of this property, even if the lid is left off the toothpaste tube, the contents should not flow out. These properties are down to the thickening agents and abrasives used in the toothpaste giving the paste its characteristic rheological properties. Ahuja et al found that the shape viscosity correlates with the yield stress and instantaneous viscosity maximum and that the addition of xanthan gum to a formulation strengthens the shape retention of the toothpaste after it has been squeezed from the tube and thickening silica reduces the stringiness [158]. 


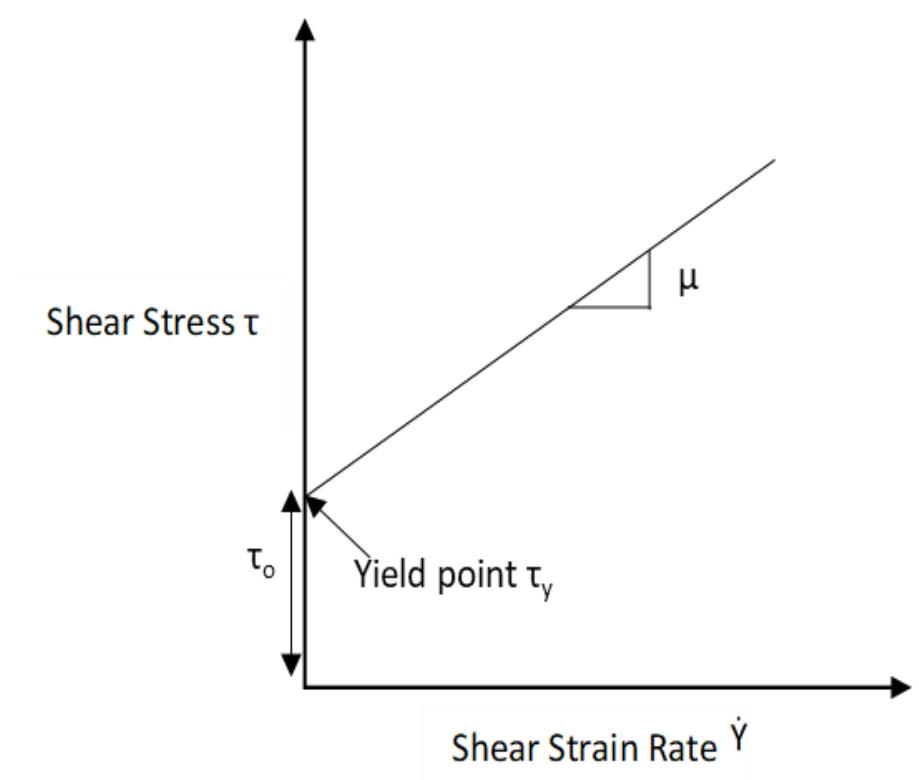

Figure 7. The Bingham graph where $\mu$ is plastic viscosity and $\tau_{0}$ is shear yield stress shows a material that behaves as a Bingham plastic will not flow until a certain amount of yield stress is applied. Once this barrier has been overcome, the flow rate will increase at a steady rate as shear stress increases.

When a tube of toothpaste is squeezed, shear forces are applied to the sides of the tube. The shear stress $(T)$ can be represented as $T=F / A$. By applying this force, the volume inside the tube is changed and in turn is imparting work on the paste. The displacement of the toothpaste from the tube can be represented as $d L=P d V$ whereby displacement $(d L)$ is equal to the pressure $(P)$ being applied and the change in the volume of the system $(d V)$.

The paste itself is incompressible and will flow out of the tube through the path of least resistance. As soon as this force is reduced or stops, the paste stops flowing. Therefore toothpaste does not sink into the bristles on a toothbrush but when you start brushing your teeth turns into a liquid $[152,159]$.

When looking at the retention of toothpaste in the mouth, it is first important to look at brushing time as the time allowed for the delivery of toothpaste to the oral cavity plays a big role in the effectiveness of the active ingredients. Oral health experts recommend brushing your teeth for 120 seconds to allow for the effective removal of plaque and to allow the active ingredients time to work. A study by Creeth et al found that brushing for $120 \mathrm{~s}$ removed $26 \%$ more plaque than brushing for $45 \mathrm{~s}$ and that brushing for $180 \mathrm{~s}$ removed $55 \%$ more plaque than brushing for $30 \mathrm{~s}$ [160]. The retention time of toothpaste is very low as immediately after brushing, the toothpaste slurry formed in the oral cavity is spat out leaving behind the active ingredients, flavours and some abrasive residue. As mentioned above, these thickening agents have mucoadhesive properties; however, little work has been done studying the retentive effect of these conventional thickening agents' in toothpaste formulations but work has been carried out on incorporating particles with mucoadhesive properties. Microparticles composed of chitosan, glutaraldehyde and fluoride have been investigated by Keegan et al showing a fast burst release followed by a slow release of fluoride over 6h [161]. However, these particles had low bioadhesive properties due to the fluoride ions that were present on the surface of the particles, 
shielding the positive charge of the chitosan. Gelatine and ethylcellulose particles again with fluoride have also been tested showing a sustained release over $8 \mathrm{~h}$ but these results are yet to be produced in vivo [162]. The amount of toothpaste used to brush teeth logically plays a role in the amount of active ingredients retained in the oral cavity after brushing. However, brushing with an excess of toothpaste will cause more foam to be generated impacting the users experience, causing too much fluoride to be retained and leading to fluorosis or could lead to the excessive ingestion of fluoride leading to fluoride poisoning as a small amount of toothpaste is always ingested. Not rinsing your mouth out after brushing is recommended as it allows for the salivary fluoride and active ingredients to be retained for longer.

\subsection{Pharmacokinetics}

The delivery and retention of therapeutic ingredients contained within oral care products is essential to their performance. A low retention time of a compound that cannot reach the desired active site will have a minimal affect. To understand how the body affects the xenobiotic or chemicals which are administered, a look at the pharmacokinetics of the active ingredients is needed. In order to ensure the effectiveness of bleaching and active agents in toothpaste, their physicochemical characteristics must allow their therapeutic action whilst not damaging the oral tissues [163]. Fluoride compounds are the most studied active ingredient in the oral cavity because of its ability to remineralize enamel, kill bacteria and protect teeth. A variety of fluoride compounds are used in toothpaste due to their properties or because of interactions within the oral cavity or to other ingredients in the toothpaste. Formulations with sodium monofluorophosphate and calcium carbonate have been shown to have a better anti-caries effect when used together because the higher levels of calcium provided by the calcium carbonate help with the remineralization of the enamel surfaces and calcium carbonate is able to neutralise acids and harmful effects caused by plaque biofilms [164]. However, if sodium fluoride is used with calcium carbonate, the anti-caries effect offered by the fluoride is offset by the calcium as ionic fluoride reacts with the anionic calcium to form insoluble calcium fluoride stopping free fluoride from entering the saliva and mucosal reservoirs.

Once applied to the oral cavity, the fluoride comes into contact with saliva. The saliva acts as a reservoir for the fluoride as well as a way of eliminating it from the oral cavity over several hours. A cycle of reapplication is needed each day for the fluoride compounds to be effective as after brushing, salivary fluoride concentration falls rapidly to below $1 \mathrm{ppm}$ within 30 to 60 minutes regardless of application type (toothpaste, tablets, gum, etc.) [159]. Work by Aasenden et al showed there is a linear relationship between log $\left(\mathrm{F}^{-}\right)$and log (time) with respect to fluorides clearance from the oral cavity [165]. Fluoride concentration and retention in saliva can also be affected by ingredients in the toothpaste. Bruun et al found that if flavouring agents were exempted from fluoridated toothpaste, a higher salivary fluoride concentration was found after brushing compared to standard formulations with flavourings [166]. They hypothesised that this was due to the stimulation of salivary flow caused by the flavour with work by Duckworth and Jones confirming this [167]. Surfactants commonly used in toothpaste have the potential to also interact with fluoride compounds. SLS has been shown to impact fluoride delivery when sodium monofluorophosphate is used by interfering with the phosphatase enzymes in plaque and saliva that facilitate release of ionic fluoride from the monofluorophosphate anion [132]. Because of this, sodium monofluorophosphate is not used in combination with SLS. Fluoride like other active ingredients, can be absorbed into the oral soft tissue 
where it is retained in a reservoir similar to saliva. Larsen et al found that there was a higher fluoride concentration in oral mucosa than in saliva after brushing with fluoride toothpaste suggesting that the oral mucosa also acts as a reservoir for fluoride [168]. Oral fluoride reservoirs are easily depleted by water exposure, with post topical applications of salivary fluoride levels dramatically decreasing [169170].

As well as fluorides, other active ingredients present in toothpaste formulations are $\mathrm{CHX}$, triclosan and metal ions such as zinc $\left(\mathrm{Zn}^{2+}\right)$ and tin $\left(\mathrm{Sn}^{2+}\right)$ which are all included for their antimicrobial activity. Much like fluorides, these compounds are eliminated from the oral cavity quickly after application by deglutition or being rinsed away by a mouth rinse or drink. These active ingredients are either positively charged or electrostatically neutral at $\mathrm{pH}$ values associated with toothpaste and can interact with the negatively charged surfaces of oral tissues and bacteria [159]. However, SLS which is found in nearly all toothpaste formulations can interact and inactivate these positively charged antimicrobials. CHX and SLS have been shown to be incompatible together even after a 30 min interval between brushing with toothpaste and rinsing with $\mathrm{CHX}$ solution as the antiplaque affect if $\mathrm{CHX}$ was reduced significantly [171]. For this reason $\mathrm{CHX}$ is not normally added to toothpaste but is included in mouthrinses.

Triclosan is generally administered as a rinse but can be administered in a toothpaste. Its use in rinses and toothpastes has recently declined due to antibacterial resistance and because it is potentially carcinogenic. Triclosan much like other active ingredients is retained in the salivary reservoir once applied. In addition to this, the enamel surface may also act as a reservoir, helping to protect against mild acid attack [159]. Although triclosan has proven antimicrobial affects, when it is included in a toothpaste, it does not increase the efficacy of the toothpaste as the other antimicrobial agents present are already adequate [159]. Once triclosan has been removed from the oral cavity, it is metabolised and excreted from the body.

Zinc is used in the form of nanoparticles in some toothpaste formulations as it exhibits antimicrobial properties. Upon administering zinc to the oral cavity, much like fluoride it enters the salivary, mucosal and enamel reservoirs. Zinc is cleared from the oral cavity bi-modally with the concentration falling rapidly over 30-60 minutes post application with the loosely bound zinc being cleared and a low concentration of more firmly bound zinc persisting for many hours afterwards [172]. Saxton et al looked at the pharmacokinetic data for zinc concentrations after application from a mouthwash and dentifrice with higher concentrations of zinc being observed in saliva 3-4 $\mathrm{h}$ after brushing and plaque growth being reduced 16 to $22 \mathrm{~h}$ after denitrifies containing $0.5 \%$ zinc citrate were applied [173]. When inside the oral cavity, zinc competes with soluble calcium for bacterial binding sites. Zinc is also readily absorbed by hydroxyapatite forming zinc-hydroxyapatite however it is readily desorbed from the hydroxyapatite by calcium [172].

The pharmacokinetics of fluoride and triclosan has been investigated in several studies. Duckworth and Morgan looked at the retention of fluoride in the oral cavity after application [159, 170]

In a paper [159] on the pharmacokinetics of fluoride in the oral cavity, Duckworth wrote how the concentration of fluoride in saliva $\left(F_{s}\right)$ as a function of time $(t)$ can be given as:

$$
d F_{S}(t) / d t=k_{1} F_{R}(t)-k_{2} F_{S}(t)-k_{3} F_{S}(t)
$$


where $F_{R}(t)$ is the concentration of fluoride in the oral reservoir, $k_{1}$ is the rate constant for the uptake of fluoride by the reservoir, $\mathrm{k}_{2}$ is the rate constant for the release of fluoride from the reservoir and $k_{3}$ is the rate constant for the elimination of fluoride from the oral cavity by swallowing. This equation can lead to:

$F_{s}(t)=A \exp (-\alpha t)+B \exp (-\beta t)$

where $A$ and $B$ are arbitrary constants and $\alpha$ and $\beta$ are functions of the three rate constants $k_{1}, k_{2}$ and $k_{3}[159]$.

By being able to calculate the concentration of fluoride and the rate at which it is eliminated, the same model can be applied to other active ingredients like triclosan and provide a greater understanding of how these compounds behave in the body. This knowledge will help to shape future advances in the retention of active ingredients.

As toothpaste acts as a storage and delivery medium to deliver active ingredients and the main ingredient holding the formulation together is a polymeric binder, a look at the Ritger-Peppas and Korsmeyer-Peppas kinetic model describing how drugs are released from a polymeric system will be the focus of this section. Using the Ritger-Peppas and Korsmeyer-Peppas models, an exponential relationship between the release of a drug from polymeric system and time can be shown using the following equation:

$f_{1}=\frac{M i}{M \infty}=K t^{n}$

where $f_{1}$ is the amount of drug that is released, $t$ is time, $M_{i}$ is the amount of drug released over time, $M \infty$ is the amount of drug at the equilibrium state, $K$ is the constant of incorporation of structural modifications and geometrical characteristics of the system and $n$ is the exponent of release [1]. This equation can be adapted to include the latency time to incorporate the beginning of a drugs release from the polymeric system $(l)$ :

$\frac{M(i-l)}{M \infty}=K(t-l)^{n}$

As toothpaste is a very complex system with multiple compounds and drugs being released either all at once or at various stages of the brushing process, the power law model allows for the study of drug release from a complex polymeric system. The value of the exponent of release that adjusts best to the release profile of an active compound in the system allows for a classification of the system as either one that follows a Fickian model or a Non-Fickian model [174]. In a Fickian model $(n=0.5)$, the drug release is governed by diffusion as the solvent transport rate or diffusion is greater than the process of polymeric chain relaxation and in a Non-Fickian model $(n=1)$, the drug release from the polymeric system corresponds to zero order release kinetics, where the mechanism driving the release is the relaxation or swelling of the polymeric chains [174]. Bansal et al looked at gels that could release levofloxacin and metronidazole in controlled manner for the treatment of periodontitis [175]. In their work, they found that the mechanism for drug release followed the Korsmeyer-Peppas with $n$ being less than 0.5 indicating a Fickian diffusion release pattern [175]. 


\section{Toothpastes as a controlled release system}

Oral care products have come a long way from the rudimental formulations designed to clean teeth and freshen breath by removing plaque and delivering flavour compounds. As new discoveries and the needs of consumers have changed, toothpaste are no longer a simple formulation that only carries out one job. Instead, a modern formulation will be able to deliver active and inactive ingredients to the oral cavity. As the active ingredients need to reach and be sustained at their active site for certain duration to gain the most benefit, methods for increasing their residence time have been incorporated into formulations. Toothpaste actives have a very short effect on the teeth as after brushing, fluorides and other active compounds are quickly removed. As these compounds cannot form suitably strong bonds, they are either removed through rinsing of the mouth with mouthwash or other liquids, swallowing or are absorbed into the blood through diffusion and taken away from the oral cavity. The delivery and sustained release of active ingredients in toothpaste has the potential to create formulations which are capable of protecting and repairing teeth to a greater extent than what is possible now. By offering these improved characteristics, the prevalence of tooth decay, gum disease, minor dental disease and cost of treating these afflictions could decrease worldwide. As toothpaste is already a suitable medium to store and carry micro- or macroparticles, novel compounds can be loaded into formulations easily and tested.

Mucoadhesive particles have been used to treat a variety of oral diseases although their application in toothpastes has only started to be researched. Incorporating these particles filled with active ingredients into novel formulations will allow for their sustained release over a longer time frame than conventional toothpaste. Micro and nanoparticles (NPS) made from chitosan have been studied as controlled release systems for oral care active ingredients. Chitosan has proven mucoadhesive properties, is nontoxic, easily removable from organisms and is capable of forming micro and NPS making it an ideal drug carrier for use in toothpaste and oral care products [176-178]. Liu et al showed sustained release of toothpaste actives from chitosan NPS for at least $10 \mathrm{~h}$ on their tooth analogues [179]. Aksungur et al (2004) looked at the use of chitosan as a delivery system for the treatment of oral mucositis, concluding that the use of a chitosan gel containing nystatin on the oral cavity provided significant healing and extended the retention time in the oral cavity due to its bioadhesive properties [180]. In addition to the standard active ingredients, antifungals, chemoprevention agents and medicinal drugs can be incorporated into particles or encapsulated and added to formulations [181183]. US patent US20140056949 discusses a controlled release mucoadhesive formulation for a chemoprevention agent incorporated into toothpastes, mouthwashes and chewing gum for the suppression of oral cancer and precancerous cells [181]. As the controlled release system is incorporated into oral care formulations, patient compliance and conformity was very high. Antimicrobial compounds commonly used in oral care products can be incorporated into NPS to aid in their delivery and sustained release in the oral cavity. Chlorohexidine is used in mouthwashes and specialised toothpaste but is quickly removed from the oral cavity after cleaning/spitting. To control and sustain its release, Verraedt et al introduced $\mathrm{CHX}$ diacetate into the pores of amorphous microporous silica [184]. By having the pore size of the silica less than $1 \mathrm{~nm}$, a sustained slow release of chlorohexidine was achieved. The addition of a mucoadhesive grafting onto the surface of the silica would allow the adhesion of the silica onto the mucosal surface and the slow release of antimicrobials, drugs and compounds. WO patent WO2000006208A1 describes a toothpaste formulation that contains antimicrobial ceramic particles which are encapsulated in polymeric gel so they can impart a substantial antimicrobial activity in the limited time available during brushing [185]. The incorporation 
of NPS into oral care products is a rapidly expanding field. Various toothpastes and mouth-rinses contain nano-hydroxyapatite, used to seal dental tubules, reducing dental hypersensitivity [186].

Chewing gums bridge the gap between the traditional two brushing periods and offer a respite for our teeth by reducing plaque acid, removing foreign bodies and plaque whilst freshening the user's breath. Using chewing gum as a short term release mechanism allows for the delivery of active ingredients into the oral cavity. The short amount of time the gum is in the mouth means the compounds must be able to diffuse out of the gum and into the oral cavity at a fast and controlled rate so as to maximise their effectiveness. Na et al looked at incorporating the anti-microbial peptide KSL as an antiplaque agent in a chewing gum formulation [187]. The study concluded that the novel gum formulation had a promising sustained release of $70-80 \%$ of the KSL in the gum over 20 minutes of chewing. A novel antibacterial wafer designed to treat periodontitis, was designed by Bromberg et al to be applied subgingivally and showed zero-order release characteristics for at least 4 weeks [188]. Although not incorporated into an oral care product, the potential for a new oral care delivery system where films, wafers and gums can be applied to in the oral cavity and their active ingredients can be used to treat, repair and protect the oral cavity where traditional oral care products are not available or not enough to fulfil the requirements of the user.

As flavour compounds are volatile, changes due to oxidation, heating and other physical and chemical interactions can change their sensory perception. Encapsulation provides excellent protection, improves stability and allows for controlled release of volatile and active compounds. All these benefits allow a volatile compound such as the flavours found in toothpaste to be delivered and sustained in the oral cavity for longer than if they were unprotected. The encapsulation of essential oils is a well-researched area due to the volatility of the oils. US patent 3957964 describes a toothpaste that contains encapsulated flavourings such as menthol and eucalyptol and the intensity of the flavour can be used to indicate whether brushing should be continued or ceased [189]. Toothpastes themselves have also been encapsulated to allow for storable single dose cleaning. US patent US4427116A discusses a predetermined amount of toothpaste that was encapsulated in non-toxic gelatine capsules where the user needs to bite down on the capsule to release the contents allowing for cleaning without a toothbrush [190]. Additionally, US patent 7074390 describes a similar invention with the addition of Miswak fibres to act as a natural toothbrush [191].

\section{Future challenges}

Oral care formulations have become a sophisticate multipurpose product capable of sustaining the release and residence time of active ingredient in the oral cavity, treating minor dental diseases and disorders whilst cleaning and providing protection throughout the day. More is known about what causes dental caries, sensitive teeth and other oral ailments and formulations to treat these have rapidly advanced. Even with these advances, continued research is leading to the development of new formulations which offer improved properties and protection over current formulations. New flavours and textures as well as a product which provides even greater quality of care will continue to be developed. When developing a complex product like toothpaste which contains multiple reagents and compounds there will always be challenges. The combination of 
antibacterial/antifungal agents need to be strong enough to eliminate most if not all the bacteria and fungi from the mouth. Too little will allow the surviving organism to become resistance to the antimicrobial/antifungal compounds used, creating issues in the future.

Modern toothpastes as discussed above contain a wide array of therapeutic ingredients that need to be retained in the oral cavity for as long as possible to be most effective. One of the most important therapeutic ingredients included in oral care products is fluoride. Being able to retain fluoride even if it is a low concentration in the oral cavity for longer will help promote remineralisation and inhibit the production of acids by plaque bacteria [192-194]. Duckworth and Morgan showed that the concentration of fluoride decreased rapidly for the first 40-80 minutes and then slowed down over the next 100-140 minutes [171]. The challenge is how to increase the retention of active ingredients. The flow of saliva and deglutition (swallowing), rinsing the oral cavity out after brushing teeth and the consumption of food and drinks reduces the concentration of active ingredients throughout the day. To overcome this, a method of retaining active ingredients is needed.

Cook et al looked at how CMC which is used in the food and pharmaceutical industry can modify the retention of sodium over time [195]. These studies showed that using a mucoadhesive polymer allowed for improved retention of sodium on the mucosa. With further research on the use of mucoadhesive polymers and their application to oral care formulations, an increase in retention of active ingredients may be achieved.

Triclosan (TCS) is a commonly used antibacterial/antifungal agent found in certain toothpastes and mouthwashes. Whilst being an effective antimicrobial, there is divided opinion on the safety of the compound. Recently questions about the excessive use of TCS and its potential carcinogenic properties have led to uncertainty around its safety for long term use in formulations [188]. There is major concern that the widespread use of TCS in everyday products will lead to antibiotic resistance and the increase in usage and availability will accelerate this [196-198]. Skovgaard et al found that pathogenic bacteria, like $S$. epidermidis have started to build up a resistance to TCS which in turn will require the use of new antimicrobial compounds to replace TCS [196]. The study looked at bacteria of the same type which had been isolated in 1965 and present day and compared their resistance to TCS. Of the samples tested, $12.5 \%$ of the present-day bacteria were found to have tolerance towards TCS [196]. Although the build-up in tolerance is not a major concern just yet, if this trend is to continue and pathogenic bacteria become resistant to other widely used antibacterial/antifungal agents, this could have a serious impact on the environment in the future [199-200]. The use of TCS in such a wide variety of products has led to detection in aquatic ecosystems, which may pose an ecological problem as it is highly toxic to algae and could lead to the death of wildlife which rely on algae for nutrients future [199-200]. If a regular supply of TCS gets into surface waters, TCS resistance among benthic microbial communities such as bacteria, fungi and crustaceans will eventually occur future [199-200]. In the future, new antibacterial /antifungal agents will need to be developed to combat resistance.

Another concern is that TCS may be a potential carcinogen with some studies linking the use of TCS and cancer [201-203]. Yueh et al found that in mice, long term exposure to TCS at elevated levels can lead to liver damage and hepatocellular carcinoma development [201]. However, these tests were only carried out on mice and the exposure to TCS in excess of their metabolic capacity which although possible in humans it is very unlikely. On the other hand, Lu and Archer (2005) used TCS as a fatty acid synthase inhibitor to suppress mammary tumorigenesis in rats [203]. The 
experiments found that, by administering $1000 \mathrm{mg} / \mathrm{kg}$ TCS into the rats' diets, a 33\% decrease in tumour multiplicity and a $38 \%$ reduction in tumour incidence was observed. Due to the need for further research and long-term human trials, more evidence is needed before a conclusive decision can be made. Much like TCS, CHX is an antimicrobial commonly used in mouthwashes and toothpaste. Although it is very effective at what it does, persistent or overuse of $\mathrm{CHX}$ has been known to stain teeth [204]. Finding an alternative or a being able to reduce staining caused by CHX would help improve products that use $\mathrm{CHX}$ and allow it to be used more long term than a few weeks.

Nanotechnology is set to influence nearly every aspect of medicine and dentistry in the near future. Particles on a nanoscale can confer specific or amplified behaviours over those used on a macro scale. The particles can have their chemical reactivity changed and their potential to penetrate and interact with living organisms. Their small size also makes their incorporation into dentifrice and mouthwashes easier and nanocomposites, microfills and gels containing nanoparticles are currently used and are being extensively researched. Microfills have potential applications in permanently replacing silver amalgam and other metals which are used in dental fillings, but more advances are needed to match the strength of the currently used metals [205]. Nano silver is already incorporated into some toothpastes such as Coral Nano Silver toothpaste as an antibacterial agent and to control halitosis. Coral toothpaste advertises that its $\mathrm{Ag}_{4} \mathrm{O}_{4}$ is 10 times more effective than normal silver nanoparticles at destroying bacteria. The silver particles work by removing electrons from pathogenic bacteria causing cell death. Negatively charged nanoparticles are shown to exhibit the weakest antibacterial activity with neutral nanoparticles showing an intermediate level of antibacterial activity as demonstrated by Abbaszadegan et al where silver nanoparticles with different charges had their antibacterial affects analysed [206]. In addition to their antibacterial properties, a review by Yin et al found 11 papers that reported silver nanoparticles prevented demineralization of the mineral content of teeth [207]. The protection offered against demineralization allows for fluoride free toothpastes although their effectiveness at re-mineralizing enamel is less than fluoride. The use of nanohydroxyapatite in toothpaste has been shown to be very effective at re-mineralising enamel more effectively than fluoride as it is a better source of free calcium [208-209]. It is also able to bind to bones and promote their growth / repair them after better source of free calcium surgery [210]. A study by Grocholewicz et al found that using nano-hydroxyapatite gel in combination with ozone therapy was more affective at treating initial approximal enamel and dentine subsurface lesions better than either alone [211]. NanoZNO have anti-inflammatory properties as their small size allows them to enter cells through ion channels or pores [212]. Pati et al showed that zinc oxide nanoparticles are able to disrupt the intergrity of bacterial cell membranes, reduce cell surface hydrophobicity and enhance intracellular bacterial killing by inducing reactive oxygen species production [213]. The positive charge on metal nanoparticles allows negatively charged microorganisms to attract these particles leading to oxidation, disruption of the bacterial cell membrane and deactivation of cellular enzymes and DNA [214]. The strong antimicrobial and anti-inflammatory affects offered by nanoparticles, their ability to repair and protect teeth and the inability for bacteria to become resistant to them due to the great diversity of mechanisms exerted by nanoparticles will further drive research into this area as the benefits they already offer substantial benefits. Although nanotechnology is seen as the next big innovation in oral care products, research by Eslami et al has shown that current mouthwashes containing nanoparticles such as nanoTiO 2 , nanoZnO, nanoCuO and nanoAg produced enamel discolouration comparable to or even greater than $\mathrm{CHX}$ making them not very practical to use in formulations currently [205]. Nanotechnology is a relatively new field so further advances will be 
made in the coming decades. There is a vast amount of potential in nanotechnology to improve every aspect of oral care formulations. Dentin replacement therapy and major tooth repairs, increased potency of antibacterial agents and longer enamel protection will become available over the next few decades [215-216]. Continued investment and development in nanotechnology will help to overcome many of the issues faced in dentistry and medicine.

\section{Conclusion:}

Oral care products are used daily by billions of people all around the world and continuing development of these products will yield better and more efficient formulations. An ever-expanding market and the demands of consumers calls for a product that does more than just remove plaque and provide fresh breath. The demand for formulations that can whiten teeth, remove stains or help treat minor oral ailments has increased rapidly over the last 20 years. This review looked at how advances in the last century have led to products which are able to treat ailments, whiten teeth and treat dentin hypersensitivity. Although much time, resources and research has gone into creating modern oral care products, there is still room for improvement such as increasing flavour and active ingredient retention, improving the level of protection toothpaste are able to offer throughout the day and improving tooth repair and regeneration. Further research on new ways of increasing the retention time of formulations, improving the power to remove stains and plaque and investigating the efficacy of the antibacterial agents will lead to the development of novel more effective formulations which fulfil consumers' demand.

\section{Acknowledgements:}

Authors are grateful to Dr Stephanie Bull for producing Figures 2 and 3 in this review.

\section{Funding \& support:}

This review was supported by Givaudan UK Ltd, Ashford, UK. The funding body was not involved in the conduct of the review or in the development of this article.

\section{References:}

1. R. Cheng, H Yang, M.Y. Shao, T. Hu, X.D. Zhou. Dental erosion and severe tooth decay related to soft drinks: a case report and literature review. J Zhejiang Univ Sci B, 10(5), 2009, pp. 395-399.

2. A.A. Jorn, J.P. Bruce, N.S. Lauren, O. Ignar, E.D. Floyd. Defining the Normal Bacterial Flora of the Oral Cavity. J Clin Microbiol, 43, 2005, pp. 5721-5732.

3. P.D. Marsh. Dental plaque as a biofilm and a microbial community - implications for health and disease. BMC Oral Health, 6, 2006, S14.

4. A.J. Winfield, R.M.E. Richards. Pharmaceutical practice, Churchill Livingstone, Edinburgh, 1998, pp421-423.

5. He. Xue-song, S. Wen-yuan. Oral Microbiology: Past, Present and Future. Int J Oral Sci, 1, 2009, pp. 47-58 
6. J. Moran, M. Addy, R. Newcombe. Comparison of the effect of toothpastes containing enzymes or antimicrobial compounds with a conventional fluoride toothpaste on the development of plaque and gingivitis. J Clin Periodontol, 16(5), 1989, pp. 295-299.

7. S.E. Adams, D. Arnold, B. Murphy, P. Carroll, A.K. Green, A.M. Smith, O.D. Marsh, T. Chen, R.E. Marriott, M.G. Brading. A randomised clinical study to determine the effect of a toothpaste containing enzymes and proteins on plaque oral microbiome ecology. Sci Rep, 7, 2017, 43344.

8. C. Squier, K. Brogden. Human oral mucosa: Development, structure and function. (2011). Wiley Blackwell

9. T. Johnston. Anatomy and Physiology of the Oral Mucosa. In: M. Rathbone, S. Senel, I. Pather. (eds) Oral Mucosal Drug Delivery and Therapy. Advances in Delivery Science and Technology. (2015). Springer, Boston, MA

10. S.L. Cook, S.P. Bull, L. Methven, J.K. Parker, V.V. Khutoryanskiy Mucoadhesion: A food perspective. Food Hydrocoll. 72, 2017, pp. 281-296

11. L.A. Tabak, M.J. Levine, I.D. Mandel, S.A. Ellison. Role of salivary mucins in the protection of the oral cavity. J Oral Pathol Med, 11, 1982, pp. 1-17

12. E. Neyrand. Role of saliva in oral food perception. Monogr.Oral Sci, 24, 2014, pp.61-70

13. A.M. Pedersen, A. Bardow, S. Beier Jensen, B. Nauntofte. Saliva and gastrointestinal functions of taste, mastication, swallowing and digestion. Oral Dis, 8, 2002, pp. 117-129

14. G. Holan, H.L. Needleman. Premature loss of primary anterior teeth due to trauma - potential short- and long-term sequelae. Dent Traumatol, 30(2), 2014, pp. 100-106

15. F.H. Jones. Teeth and bones: applications of surface science to dental materials and related biomaterials. Surf. Sci. Rep, 42(3-5), 2001, pp. 75-205

16. N.P. Piesco, J.W. Simmelink. Histology of enamel, in: J.K. Avery (Ed.), Oral Development and Histology, Thieme Medical Publishers Inc., New York, 1994, pp. 153-171

17. A.R. Ten Cate. 1994. Oral Histology: Development, Structure and Function, 4th Edition, Mosby. Maryland Heights. Missouri. United States.

18. J.A. Aas, B.J. Paster, L.N. Stokes, I. Olsen, Dewhirst F.E. Defining the Normal Bacterial Flora of the Oral Cavity. J Clin Microbiol, 43(11), 2005, pp. 5721-5732.

19. L. Gao, T. Xu, G. Huang, S. Jiang, Y. Gu, F. Chen. Oral microbiomes: more and more importance in oral cavity and whole body. Protein Cell, 9(5), 2018, pp. 488-500.

20. F.A. Scannapieco. Role of oral bacteria in respiratory infection. J. Periodontol, 70, 1999, pp.793802.

21. S.J. Leishman, H.L. Do, P.J. Ford. Cardiovascular disease and the role of oral bacteria. J Oral Microbiol, 2, 2010, 5781.

22. L. Trombelli, R.O. Farina, C. Silva, D.N. Tatakis. Plaque-induced gingivitis: Case definition and diagnostic considerations. J. Periodontol, 89 (1), 2018, pp. S46-73

23. P. Jorth, K.H. Turner, P. Gumus, N. Nizam, N. Buduneli, M. Whiteley. Metatranscriptomics of the human oral microbiome during health and disease. MBio, 5(2), 2014, E01012-E01014.

24. B.A. Peters, J. Wu, Z. Pei, L. Yang, M.P. Purdue, N.D. Freedman, E.J. Jacobs, S.M. Gapstur, R.B. Hayes, J. Ahn. Oral Microbiome composition reflects prospective risk for esophageal cancers. Cancer Res, 77(23), 2017, pp. 6777-6787.

25. W.J. Loesche. Role of Streptococcus mutans in human dental decay. Microbiol Rev, 50, 1986, pp. 353-380.

26. S.D. Forssten, M. Bjorklund, A.C. Ouwehand. Streptococcus mutans, Caries and Simulation Models. Nutrients, 2(3), 2010, pp.290-298. 
27. S. Fachon-Kalweit, B.L. Elder, P Fives-Taylor. Antibodies that bind to fimbriae block adhesion of Streptococcus sanguis to saliva-coated hydroxyapatite. Infect. Immun, 48(3), 1985, pp. 617624.

28. A.A. Scheie. Mechanisms of dental plaque formation. , 8(2), 1994, pp. 246-253.

29. I.M. Velsko, J.A.F Yates, F. Aran, R.W. Hagan, L.A.F Frantz, J.B.R. Martinez, E. Chaves, C. Gosden, G. Larson, C. Warinner. Microbial differences between dental plaque and historic dental calculus are related to oral biofilm maturation stage. Microbiome, 7, 2019, 102

30. P.D. Marsh. Dental plaque as a biofilm and a microbial community - implications for health and disease. BMC Oral Health, 6(1), 2006, S14.

31. P. Stoodley, L.H.B. Stoodley, Costerton, P. DeMeo, M. Shirtliff, E. Gawalt, S. Kathju. Biofilms, Biomaterials, and Device-Related Infections in the Handbook of Polymer Applications, in K. Modjarrad, S. Ebnesajjad. Medicine and Medical Devices. Norwich, NY. William Andrew. 2013. pp 77-101

32. O.Y. Yu, I.S. Zhao, M.L. Mei, E.C.M. Lo, C.H. ChU. Dental Biofilm and Laboratory Microbial Culture Models for Cariology Research. Dent. J, 5(2), 2017, 21

33. J. Featherstone. Dental caries: A dynamic disease process. Aust. Dent. J, 53(3), 2008, pp. 286-291

34. H. Colak, C.T. Dulgergil, M. Dalli, M.M. Hamidi. Early childhood caries update: A review of causes, diagnoses, and treatments. J Nat Sci Biol Med, 4(1), 2013, pp. 29-38.

35. J.B. Summitt, J.W. Robbins, R.S. Schwartz. Fundamentals of Operative Dentistry: A Contemporary Approach. 3rd ed. Hanover Park, IL: Quintessence Publishing; 2006. pp 2-4

36. C. Deveci, C. Çınar, R.E. Tirali. Dental Caries Diagnosis, Prevention and Management. Management of White Spot Lesions. London: Intech Open, 2018, pp. 129-131.

37. T.R. Sudjalim, M.G. Woods, D.J. Manton. Prevention of white spot lesions in orthodontic practice: A contemporary review. Aust. Dent. J, 51, 2006, pp. 284-289

38. M.A. Munoz, L.A. Arana-Gordillo, G.M. Gomes, O.M. Gomes, N.H. Bombarda, A Reis, A.D. Loguercio. Alternative esthetic management of fluorosis and hypoplasia stains: blending effect obtained with resin infiltration techniques. J Esthet Restor Dent, 25(1), 2013, pp. 32-39.

39. H.C. Margolis, E.C. Moreno. Kinetics of hydroxyapatite dissolution in acetic, lactic, and phosphoric acid solutions. Calcif Tissue Int, 50(2), 1992, pp. 137-143.

40. C. Dawes. What is the critical pH and why does a tooth dissolve in acid. J Can Dent Assoc, 69(11), 2003, pp. 722-724.

41. P. Muthuvel, A. Ganapathy, M.K. Subramaniam, V.D. Revankar. Erosion Infiltration Technique': A Novel Alternative for Masking Enamel White Spot Lesion. J Pharm Bioallied Sci, 9(1), 2017, S289S291.

42. B. Ogaard. White Spot Lesions During Orthodontic Treatment: Mechanisms and Fluoride Preventive Aspects. Semin Orthod, 14(3), 2008, pp.183-193.

43. R.M Love, H.F. Jenkinson. Invasion of dentinal tubules by oral bacteria. Crit Rev Oral Biol Med, 13(2), 2002, pp. 171-183

44. J.C. Farges, B. Alliot-Licht, E. Renard, M. Ducret, A. Gaudin, A.J. Smith, P.R. Cooper. Dental Pulp Defence and Repair Mechanisms in Dental Caries. Mediat Inflamm, 2015, 1-16

45. S. Shweta, S.K. Prakash. Dental abscess: A microbiological review. Dent Res J (Isfahan). 10(5), 2013, pp. 585-591

46. D.K. Rechenber, J.C. Galicia, O.A. Peters. Biological Markers for Pulpal Inflammation: A Systematic Review. PLoS One, 2016,11(11). 
47. X. Li, K.M. Kolltveit, L. Tronstad, I. Olsen. Systemic diseases caused by oral infection. Clin Microbiol Rev, 13(4), 2000, pp. 547-558.

48. E. Amponsah, P. Donkor. Life-threatening Oro-facial infections. Ghana Med J, 41(1), 2007, pp. 33-36.

49. T. Aoba, O. Fejerskov. Dental fluorosis: chemistry and biology. Crit Rev Oral Biol Med, 13(2), 2002, 155-170

50. M.R. Franzman, S.M. Levy, J.J. Warren, B. Broffittb. Fluoride dentifrice ingestion and fluorosis of the permanent incisors. JADA. 137, 2006, pp. 645-652.

51. S. Jones, B.A. Burt, P.E. Petersen, M.A. Lennon. The effective use of fluorides in public health, Bulletin of the WHO, 83, 2005, pp. 670-676.

52. D. Kanduti, P. Sterbenk, B. Artnik. Fluoride: A review of use and effects on health. Mater Sociomed, 28(2), 2016, pp. 133-137

53. P. Gasser, Y. Haikel, J.C. Voegel, Ph. Gramain. Surface reactions of hydroxyapatite in the presence of fluoride ions 2. Effects of calcium and phosphate in saturated solutions. Colloids Surf. A Physicochem. Eng. Asp, 88(2-3), 1994, pp. 157-168

54. R.E. Marquis. Antimicrobial actions of fluoride for oral bacteria. Can J Microbiol, 41(11), 1995, pp. 955-964

55. I.R. Hamilton, G.H.W. Bowden. Fluoride effects on oral bacteria. In: O. Fejerskov, J. Ekstrand, B.A. Burt. Fluoride in dentistry. Copenhagen: Munksgaard, 29(2) 1996, pp. 230-251.

56. G.K. Stookey, T.A. Barnhard, B.R. Schemehorn. In vitro removal of stain with dentifrices. J Dent Res, 61(1), 1982, p.p. 1236-1239

57. A. Joiner, M.J. Pickles, C. Tanner, E. Weader, P. Doyle. An in situ model to study the toothpaste abrasion of enamel. J. Clin. Periodontol. 31, 2004, pp. 434-438

58. H. Nordbo. Discoloration of dental pellicle by tannic acid. Acta Odontol. Scand. 35, 1977, pp. 305-310

59. G.J.P.L. de Oliveira, J.M. de Aveiro, R.A.C. Marcantonio. Influence of different toothpaste abrasives on the bristle end-rounding quality of toothbrushes. Int J Dent Hygiene. 13, 2014, pp. 18-24.

60. G. Planisic. Explore your toothpaste. Phys. Educ, 41(4), 2006, pp. 311-316

61. M.C. Ferreira, M.L. Ramos-Jorge, A.C.B. Delbem, R.S. Vieirac. Effect of Toothpastes with Different Abrasives on Eroded Human Enamel: An in situ/ex vivo Study. Open Dent J, 7, 2013, pp.132-139

62. S. Hooper, N.X. West, M.J. Pickles, A. Joiner, R.G. Newcombe, M. Addy. Investigation of erosion and abrasion on enamel and dentine: a model in situ using toothpastes of different abrasivity. $J$ Clin Periodontol, 30, 2003, pp 802-808.

63. G.V. Samsonov. Handbook of the Physicochemical Properties of the Elements. Springer. Boston. United States. 1968, pp. 387-466

64. C.M.L. Bollen, P. Lambrechts, M. Quirynen. Comparison of surface roughness of oral hard materials to the threshold surface roughness for bacterial plaque retention: A review of the literature. Dent Mater.13, 1997, pp. 258-269.

65. M. Quieyen, M. Marechal, H.J. Busscher, A.H. Weerkamp, P.L. Darius, D. van Steenberghe. The influence of surface free energy and surface roughness on early plaque formation. J Clin Periodontol, 17, 1990, pp. 138-144.

66. R.D. Nogueria, C.B. Silva, C.P. Lepri, R.G. Palma-Dibb, V.R. Geraldo-Martins. Evaluation of Surface Roughness and Bacterial Adhesion on Tooth Enamel Irradiated With High Intensity Lasers. Braz Dent J, 28, 2017, pp. 24-29 
67. J. Martos, A. Gewehr, E. Paim. Aesthetic approach for anterior teeth with enamel hypoplasia. Contemp Clin Dent, 3(1), 2012, pp. 82-85.

68. T.S. Tilliss, D.J. Stach, G.N. Cross-Poline. Use of toothpicks for chlorhexidine staining. J Clin Periodontol, 19(6), 1992, pp. 398-400

69. N. Claydon, L.Hunter, J. Moran, W. Wade, E. Keity, R. Moverl, M. Addy. A 6-month home-usage trial of $0.1 \%$ and $0.2 \%$ delmopinol mouthnashes. (I). Effects on plaque, gingivitis, supragingival calculus and loath staining. J Clin Periodonto, 23, 1996, pp. 220-228.

70. R. Yates, S. Jenkins, R. Newcombe, W. Wade, J. Moran, M. Addy M. A 6-month home usage trial of a $1 \%$ chlorhexidine toothpaste (1). Effects on plaque, gingivitis, calculus and toothstaining. J Clin Periodontol, 20(2), 1993, pp.130-138.

71. A. Watts, M. Addy. Tooth Discolouration and Staining: Tooth Discolouration and Staining: A Review of the Literature. Brit Dent J, 109(6), 2001, pp. 309-316.

72. H.B. Yaacob, A.B. Mahfuz Ali, J.A.Hamid. The prevalence of tetracycline--stained teeth in Malaysians--a preliminary survey. Med J Malaysia, 38(3), 1983, pp. 197-199

73. M. Biria, F.M. Abbas, S. Mozaffar, R. Ahmadi. Dentinogenesis imperfecta associated with osteogenesis imperfecta. Dent Res J, 9(4), 2012, pp. 489-494

74. M. Epple, F. Meyer, J. Enax. A Critical Review of Modern Concepts for Teeth Whitening. Dent J (Basel), 7(3), 2019, pp. 79

75. E.E. Masterson, J.C. Barker, K.S. Hoeft, S. Hyde. Shades of Decay: The Meanings of Tooth Discoloration and Deterioration to Mexican Immigrant Caregivers of Young Children. Hum Organ, 73(1), 2014, pp. 82-93

76. A. Joiner. Whitening toothpastes: A review of the literature. J of Dent, 38(2), 2010, pp.17-24

77. A. Baig, T. He, J. Buisson, L. Sagel, E. Suszcynsky-Meister, D.J. White. Extrinsic whitening effects of sodium hexametaphosphate-a review including a dentifrice with stabilized stannous fluoride. Compend Contin Educ Dent. 26(1), 2005, pp. 47-53

78. S. Katharine, R. Holme. 2005 US Patent 20050025721

79. C.J. Kleber, M.S. Putt, B.J. Nelson. In vitro tooth whitening by a sodium bicarbonate/peroxide dentifrice. J of Clin Dent, 9(1), 1998, 16-21

80. A. Joiner, W. Luo. Tooth colour and whiteness: a review. J of Dent, 67, 2017, pp. 3-10

81. P. Kalyana, A. Shashidhar, B. Meghashyam, K.R. Sreevidya, S. Sweta. Stain removal efficacy of a novel dentifrice containing papain and Bromelain extracts--an in vitro study. Int J Dent Hyg. 9(3), 2011, pp. 229-233.

82. T.C. Lyon, W.A. Parker, G.P. Barnes. Evaluation of effects of application of a citroxain-containing dentifrice. J Esthet Dent, 3, 1991, pp. 51-53

83. Y.A. Albarkah, R.J. Green, V.V. Khutoryanskiy. Probing the Mucoadhesive Interactions Between Porcine Gastric Mucin andSome Water-Soluble Polymers. Macromol. Biosci, 15, 2015, pp. 15461533.

84. V.V. Khutoryanskiy. Advances in mucoadhesion and mucoadhesive polymers. Macromol. Biosci, 11(6), 2011, pp. 748-764

85. A. Amit, S. Sharad, Ajazuddin, K.M. Junaid, Swarna. Theories and Factors Affecting Mucoadhesive Drug Delivery Systems: A Review. IJRAP, 2(4),2011, pp. 1155-1161

86. B.M. Boddupalli, Z.N.K. Mohammed, R.A. Nath, D. Banji. Mucoadhesive drug delivery system: An overview. J Adv. Pharm Technol Res, 1(4), 2010, pp. 381-387.

87. J.D. Smart. The basics and underlying mechanisms of mucoadhesion. Adv Drug Deliv, 57(11), 2005, pp. 1556-1568. 
88. F.C. Carvalho, M.L. Bruschi, R.C. Evangelista, M.P.D. Gremiao. Mucoadhesive drug delivery systems. Braz. J. Phram, 46, 2010, pp.1-18

89. E. Russo, F. Selmin, S. Baldassari, C.G.M. Gennari, G. Caviglioli, F. Cilurzo, P. Minghetti, B. Parodi A focus on mucoadhesive polymers and their application in buccal dosage forms. J. Drug Deliv. Sci. Tec, 32(B), 2016, pp. 113-125.

90. A. Ludwig. The use of mucoadhesive polymers in ocular drug delivery. Adv. Drug Deliv. Rev. 57, 2005, pp. 1595.

91. M.J. Cash, P.J. Cowan, G. Kroon. Soluble, associative carboxymethylcellulose, method of making, and uses thereof. European Patent Office Patent No EP 1565496 A2. 2005.

92. C.B. Hollabaugh, L.H. Burt, A.P. Walsh. Carboxymethylcellulose. Uses and Applications. Ind Eng Chem, 37(10), 1945, pp. 943-947

93. A.H. Hosmani, Y.S. Thorat, P.V. Kasture. Carbopol and its Pharmaceutical Significance: A Review. Pharm. Rev, 4(1), 2006.

94. T.M.M. Ways, W.M. Lau, V.V. Khutoryanskiy. Chitosan and its Derivatives for Application in Mucoadhesive Drug Delivery Systems. Polymers, 20(3), 2018, pp. 267.

95. R. Harris, N. Acosta, A. Heras. Chitosan and inhalers: a bioadhesive polymer for pulmonary drug delivery. 2013. pg 77-93.

96. S. Kockisch, G.D. Rees, S.A. Young, J. Tsibouklis, J.D. Smart. Polymeric Microspheres for Drug Delivery to the Oral Cavity: An In Vitro Evaluation of Mucoadhesive Potential. J. Pharm. Sci, 92(8), 2003, pp. 1614-1623.

97. F. Katzen, D.U. Ferreiro, C.G. Oddo, M.V. Ielmini, A. Becker, A. Puhler, L. Lelpi L. Xanthomonas campestris pv. campestris gum Mutants: Effects on Xanthan Biosynthesis and Plant Virulence. J Bacteriol, 180(7), 1998, pp.1607-1617.

98. A.H. Shojaei. Buccal Mucosa As A Route For Systemic Drug Delivery: A Review. J Pharm Pharmaceut Sci, 1(1), 1998, pp. 15-30

99. M. Singh, A.K. Tiwary, G. Kaur. Investigations on interpolymer complexes of cationic guar gum and xanthan gum for formulation of bioadhesive films. Res Pharm Sci, 5(2), 2010, pp. 79-87.

100. R.R. Shileder, A.A. Tagalpallewar, C.R. Kokare. Formulation and in vitro evaluation of xanthan gum-based bilayered mucoadhesive buccal patches of zolmitriptan. Carbohydr. Polym, 101, 2014, pp. 1234-1242.

101. A. Berknop-Schnurch. Thiomers: a new generation of mucoadhesive polymers. Adv Drug Deliv Rev. 3;57(11), 2005, pp. 1569-1582.

102. V.M. Leitner, G.F. Walker, A. Bernkop-Schnurch. Thiolated polymers: evidence for the formation of disulphide bonds with mucus glycoproteins. Eur J Pharm Biopharm. 56(2), 2003, pp. 207-214

103. M. Messina, H.S. Dua. Early results on the use of chitosan-N-acetylcysteine (Lacrimera ${ }^{\circledR}$ ) in the management of dry eye disease of varied etiology. Int. Ophthalmol, 39, 2019, pp. 693-696 104. R.P. Brannigan, V.V. Khutoryanskiy. Progress and Current Trends in the Synthesis of Novel Polymers with Enhanced Mucoadhesive Properties. Macromol. Biosci, 19, 2019, 1900194

105. L.J. Shine. Oral rinse composition and method. United States Patent No US 8273385 B1. 2012.

106. S. Thaweboon, B. Thaweboon. Effect of an essential oil-containing mouth rinse on VSCproducing bacteria on the tongue. Southeast Asian J Trop Med Public Health, 42(2), 2011, pp. 456 462. 
107. D.H. Fine, D. Furgang, M.L. Barnett, C. Drew, L. Steinberg, C.H. Charles, J.W. Vincent. Effect of an essential oil-containing antiseptic mouthrinse on plaque and salivary Streptococcus mutans levels. J Clin Peridontol, 27(3), 2000, 1570161

108. P.S.X. Yap, B.C. Yiap, H.C. Ping, S.H.E. Lim. Essential Oils, A New Horizon in Combating Bacterial Antibiotic Resistance. Open Microbiol J, 8, 2014, pp. 6-14.

109. H. Si, J. Hu, Z. Liu, Z. Zeng. Antibacterial effect of oregano essential oil alone and in combination with antibiotics against extended-spectrum $\beta$-lactamase-producing Escherichia coli. FEMS Immunol. Med. Microbiol, 53(2), 2008, pp. 190-194

110. M.Y. Memar, P. Raei, N. Alizadeh, A.M. Akbari, H.S. Kafil. Carvacrol and thymol: strong antimicrobial agents against resistant isolates. Clin. Microbiol. Rev. 28(2), 2017, pp. 63-68.

111. S. Shapiro, B. Guggenheim. The action of thymol on oral bacteria. Oral Microbiol Immunol, 10(4), 1995, pp. 241-246.

112. G. Nieto, E. Skaltsa. Biological Activities of Three Essential Oils of the Lamiaceae Family. Medicines (Basel), 4(3), 2017, 63

113. R. Becerril, C. Nerin , R. Gómez-Lus. Evaluation of bacterial resistance to essential oils and antibiotics after exposure to oregano and cinnamon essential oils. Foodborne Pathog Dis, 9(8), 2012, pp. 699-705.

114. S. Miglani, V. Aggarwal, B. Ahuja. Dentin hypersensitivity: Recent trends in management. J Conserv Dent, 13(4), 2010, pp. 218-224.

115. L.G. Petersson. The role of fluoride in the preventive management of dentin hypersensitivity and root caries. Clin Oral Investig, 17(1), 2013, pp. 63-71.

116. S. Poulsen, M. Errboe, Y. Lescay Mevil, A.M. Glenny. Potassium containing toothpastes for dentine hypersensitivity. Cochrane Database Syst Rev, 19(3), 2006.

117. M. Brännström. Sensitivity of dentine. Oral Surg Oral Med Oral Pathol Oral Radiol, 21 (4), 1966, pp. 517-526.

118. N. X. West, A. Lussi, J. Seong, E. Hellwig. Dentin hypersensitivity: pain mechanisms and aetiology of exposed cervical dentin. Clin Oral Investig. 17(1), 2013, pp. 9-19.

119. M. Nähri, E. Jyväsjärvi, A. Virtannen. Role of intradental A- and C- type fibres in dental pain mechanisms. Proc Finn Dent Soc. 88(1), 1992, pp. 507-516

120. J.H. Irvine. Root surface sensitivity: A review of aetiology and management. J N Z Soc Periodontol, 66, 1988, pp. 15-18.

121. P.M Bartold. Dentinal hypersensitivity: a review. Aust Dent J, 51(3), 2006, pp. 212-218

122. A.J. Charig, S. Thong, F. Flores, S. Gupta, E. Major, A.E. Winston. Mechanism of action of a desensitizing fluoride toothpaste delivering calcium and phosphate ingredients in the treatment of dental hypersensitivity. Part II: comparison with a professional treatment for tooth hypersensitivity. Compend Contin Educ Dent, 30(9), 2009, pp. 622-628.

123. J. MacDonald, R. Hayman. Dental compositions with sensitivity relief United States patent No US 8652445 B2. 2014.

124. H.T. Leinen, P. Wulknitz. Oral and dental hygiene products for sensitive teeth. World Interllectual Property Organization patent No WO 1999003445 A2. 1999.

125. B.F.A. Karim, D.G. Gillam. The Efficacy of Strontium and Potassium Toothpastes in Treating Dentine Hypersensitivity: A Systematic Review. Int. J. Dent, 2013:573258.

126. S.Y. Shen, C.H. Tsai, L.C. Yang, Y.C. Chang. Clinical efficacy of toothpaste containing potassium citrate in treating dentin hypersensitivity. J. Dent. Sci, 4(4), 2009, pp. 173-177. 
127. R. Orchardson, D.G. Gillam. The efficacy of potassium salts as agents for treating dentin hypersensitivity. J. Orofac .Pain, 14(1), 2000, pp. 9-19.

128. R. Garberoglio, M. Brännström. Scanning electron microscopic investigation of human dentinal tubules. Arch. Oral Biol, 21, 1976, pp. 355-362

129. M. Nähri, E. Jyväsjärvi, A. Virtannen. Role of intradental A- and C- type fibres in dental pain mechanisms. Proc .Finn Dent. Soc, 88(1), 1992, pp. 507-516.

130. A.R Davari, E. Ataei, H. Assarzadeh. Dentin Hypersensitivity: Etiology, Diagnosis and Treatment; A Literature Review. J Dent (Shiraz), 14(3), 2013, pp. 136-145.

131. I.H. Lindenmuller, J.T. Lambrecht. Oral care. Curr. Probl. Dermato.I, 40, 2011, pp. 107- 115.

132. A.G. Stovell, B.M. Newton, R.J.M. Randall. Important considerations in the development of toothpaste formulations for children. Int. Dent. J, 63(2), 2013, pp. 57-63

133. S. Salzer, N.A.M. Rosema, E.C.J. Martin, D.E. Slot, C.J. Timmer, C.E. Dorfer, G.A. van der Weijden. The effectiveness of dentifrices without and with sodium lauryl sulfate on plaque, gingivitis and gingival abrasion-a randomized clinical trial. Clin Oral Investig, 20, 2016, pp. 443-450.

134. A. Nordstrom, C. Mystikos, P. Ramberg, D. Birkhed. Effect on de novo plaque formation of rinsing with toothpaste slurries and water solutions with a high fluoride concentration (5,000 ppm). Eur. J. Oral. Sci, 117(5), 2009, pp. 563-567.

135. A.S. Landa, B. van de Belt-Gritter, H.C. van der Mei, H.J. Busscher. Recalcitrance of Streptococcus mutans biofilms towards detergent-stimulated detachment. Eur. J. Oral Sci, 107, 1999, pp. 236-243

136. I. Effendy, H.I. Maibach. Surfactants and experimental irritant contact dermatitis. Contact Derm, 33, 1995, pp. 217-225

137. E. Vranic, A. Lacervic, A. Mehmedagic, A. Uzunovic. Formulation Ingredients for Toothpastes and Mouthwashes. Bosnian J. Basic Med. Sciences, 4(4), 2004, pp. 51-58

138. U. Kaczmarek, B. Pregiel, A. Wrzyszcz-Kowalczyk, I. Grzesiak, K. Fita. Fluoride levels in saliva after tooth-brushing using fluoride toothpastes with and without rinsing of oral cavity. Ann. Acad. Med. Stetin, 52(1), 2006, pp. 45-49.

139. R.M. Duckworth, A. Maguire, N. Omid, I.N. Steen, G.I. McCracken, F.V. Zohoori. Effect of rinsing with mouthwashes after brushing with a fluoridated toothpaste on salivary fluoride concentration. Caries Res, 43(5), 2009, pp. 391-396

140. K. Sotthipoka, P. Thanomsuk,R. Prasopsuk, C. Trairtvorakul, K. Kasevayuth. The effects of toothpaste amounts and post-brushing rinsing methods on salivary fluoride retention. J.Health Res, 32(6), 2018, pp. 421-431

141. M.W. Haq, M. Batool, S.H. Ahsan, N.R. Qureshi. Alcohol use in mouthwash and possible oral health concerns. J. Pak. Med. Assoc, 59(3), 2009, pp. 186-190

142. D. Oneschuk, N. Hagen, N. MacDonald. Palliative Medicine: A case-based manual 3rd ed. Oxford University Press. UK. 2012, pp. 126

143. S. Currie, C.S. Farah. Alcohol-containing mouthwash and oral cancer risk: a review of current evidence. OA Alcohol, 10;2(1), 4, 2014.

144. S. Gandini, E. Negri, P. Boffetta, C. La Vecchia, P. Boyle. Mouthwash and oral cancer risk quantitative meta-analysis of epidemiologic studies. Ann. Agric. Environ. Med, 19(2), 2012, pp. 17380.

145. A. Chaudhari, H. Scheurer, P. Pan, F. Volpe. US 5817295 A. 1998. 
146. A. Jose, A. Butler, D. Payne, R. Maclure, P. Rimmer, M. L. Bosma. A randomised clinical study to evaluate the efficacy of alcohol-free or alcohol-containing mouthrinses with chlorhexidine on gingival bleeding. Brit. Dent. J, 219, 2015, pp. 125-130

147. C.P. Broedersz, K.E. Kasza, L.M. Jawerth, S. Münster, D.A. Weitz, F.C. MacKintosh. Measurement of nonlinear rheology of cross-linked biopolymer gels. Soft Matter, 6, 2010, pp. 41204127.

148. L. Martinetti, A.M. Mannion, W.E. Voje, R. Xie, R.H. Ewoldt, L.D. Morgret, F.S. Bates, C.W. Macosko. A critical gel fluid with high extensibility: The rheology of chewing gum. J Rheol, 58, 2014, pp. 821-838.

149. G. Tabilo-Munizaga, G.V. Barbosa-Cánovas. Rheology for the food industry. J.Food Eng, 67(12), 2005, pp.147-156

150. B.A. Lindquist, R.B. Jadrich, D.J. Milliron, T.M. Truskett. On the formation of equilibrium gels via a macroscopic bond limitation. J.Chem. Phys, 145(7), 2016

151. J.D. Ferry. Viscoelastic Properties of Polymers, 3rd Edition. Wiley. 1980, pp 412

152. R.J. Stokes, D. Rennell Evans. Fundamentals of Interfacial Engineering, Wiley-VCH, New York. United States. 1997, pp94-95

153. Z. Liu, L. Liu, H. Zhou, J. Wang, L. Deng. Toothpaste microstructure and rheological behaviours including aging and partial rejuvenation. Korea-Australia Rheology Journal. 27(3), 2015, pp. 207-212

154. H.A. Ardakani, E. Mitsoulis, S.G.Hatzikiriakos. Thixotropic flow of toothpaste through extrusion dies. J Nonnewton Fluid Mech. 166, 2011, pp. 1262-1271

155. Z. Liu, L. Liu, H. Zhou, J. Wang, L. Deng. Toothpaste microstructure and rheological behaviors including aging and partial rejuvenation. Korea-Australia Rheology Journal, 27(3), 2015, pp.207-212. 156. M.C. Meilgaard, T.B. Carr, G.V. Civille. Sensory Evaluation Techniques, Third Edition. CRC Press. Cleveleand. Ohio. United States. 1999.

157. C.A. Hightower, E Chambers. Descriptive Sensory Analysis of Toothpaste Flavour and Texture Using Two Sampling Methods: Brushing Versus Spoon Tasting. J. Sens. Stud, 24, 2008, pp. 301-316 158. A. Ahuja, A. Potanin. Rheological and sensory properties of toothpastes. Rheologica Acta, 57(6-7), 2018, pp. 459-471.

159. R.M. Duckworth. Pharmacokinetics in the oral cavity: fluoride and other active ingredients. Monogr. Oral Sci, 23, 2013, pp. 125-139

160. J.E. Creeth, A. Gallagher,J. Sowinski, J. Bowman, K. Barrett, S. Lowe, K. Patel, M.L. Bosma. The effect of brushing time and dentifrice on dental plaque removal in vivo. J Dent Hyg, 83(3), 2009, pp. 111-116.

161. G.M. Keegan, J.D. Smart, M.J. Ingram, L-M. Barnes, G.R. Burnett, G.D. Rees. Chitosan microparticles for the controlled delivery of fluoride. J. Dent. 40(3), 2012, pp. 229-240.

162. L.M.B. De Francisco, J.A. Cerquetani, M.L. Bruschi. Development and characterization of gelatin and ethylcellulose microparticles designed as platforms to delivery fluoride. Drug Dev. Ind. Pharm. 39(11), 2013, pp. 1644-1650.

163. S.P. Hilgenberg, S.C.S. Pinto, P.V. Farago, F.A. Santos, D.S. Wamiber. Physical-chemical characteristics of whitening toothpaste and evaluation of its effects on enamel roughness. Braz. oral res.25(4), 2011

164. A.C.M. Brito, L.R. Danta, A.L.F.D. Brito, A.C.S. Muniz, I.A. Ramos, A.M.R. Cardoso, A.F.C. Xavier, A.L. Cavalcanti. Loss on drying, calcium concentration and $\mathrm{pH}$ of fluoride dentifrices. Contemp Clin Dent. 6(1), 2015, S: 72-S76. 
165. R. Aasenden, F. Brudevold, B. Richardson. Clearance of fluoride from the mouth after topical treatment or the use of a fluoride mouthrinse. Arch Oral Biol,13, 1968, 625-636.

166. C. Bruun, V. Qvist, A. Thylstrup. Effect of flavour and detergent on fluoride availability in whole saliva after use of NaF and MFP dentifrices. Caries Res, 21, 1987 pp. 427-434

167. R.M. Duckworth, S. Jones. On the relationship between salivary fluoride clearance and the rate of salivary flow. Caries Res, 23, 1989, 437

168. S.L. Larsen, V. Baelum, A. Richards, B. Nyvad. Fluoride in Saliva and Oral Mucosa after Brushing with 1,450 or 5,000 ppm Fluoride Toothpaste. Caries Res. 53, 2019, pp. 675-681

169. G.L. Vogel. Oral fluoride reservoirs and the prevention of dental caries. Monogr Oral Sci, 22, 2011, pp. $146-157$

170. R.M. Duckworth, S.N. Morgan. Oral fluoride retention after use of fluoride dentifrices. Caries Res, 25(2), 1991, pp. 123-129.

171. P. Barkvoll, G. Rolla, A.K. Svendsen. Interaction between chlorhexidine digluconate and sodium lauryl sulfate in viv. J. Clin. Periodontol, 16(9), 1988, pp. 593-595.

172. R.J.M. Lynch. Zinc in the mouth, its interactions with dental enamel and possible effects on caries; a review of the literature. Int Dent J.61 (3), 2011, pp. 46-54.

173. C.A. Saxton, G.J. Harrap, A.M. Llody. The effect of dentifrices containing zinc citrate on plaque growth and oral zinc levels. J. Clin. Periodontol, 13(4), 1986, pp. 301-306.

174. M.L. Bruschi. Mathematical models of drug release in Strategies to Modify the Drug Release from Pharmaceutical Systems, Elsevier, Amsterdam,2015 Chapter 5 page 74-75 section 5.6.

175. M. Bansal, N. Mittal, S.K. Yadav, G. Khan, P. Gupta, B. Mishra, G. Nath. Periodontal thermoresponsive, mucoadhesive dual antimicrobial loaded in-situ gel for the treatment of periodontal disease: Preparation, in-vitro characterization and antimicrobial study. J Oral Biol Craniofac Res, 8(2), 2018, pp. 126-133.

176. C. van Loveren. J.F. Buijs, J.M. ten Cate. The effect of triclosan toothpaste on enamel demineralization in a bacterial demineralization model. J. Antimicrob. Chemother, 45 (2), 2000, pp. 153-158.

177. S.A. Agnihotri, N.N. Mallikarjuna, T.M. Aminabhavi. Recent advances on chitosan-based micro- and nanoparticles in drug delivery. J. Control Release, 100(1), 2004, pp. 5-28.

178. K. Thanki, R.P. Gangwal, A.T. Sangamwar, S. Jain. Oral delivery of anticancer drugs: Challenges and opportunities. J. Control Release, 170, 2013, pp. 15-40

179. H. Liu, B. Chen, Z. Mao, C. Gao. Chitosan nanoparticles for loading of toothpaste actives and adhesion on tooth analogs. J. Appl. Polym, 106, 2007, pp. 4248 - 4256.

180. P. Aksungur, A. Sungur, S. Ünal, A.B. İskit, C.A. Squier, S. Şenel. Chitosan delivery systems for the treatment of oral mucositis: in vitro and in vivo studies. J. Control Release, 98(2), 2004, pp. 269279.

181. R.S. Mallery, P.E.Larsen, D.S. Gary, P.S. Schwendeman, G.K. Desai. Controlled release mucoadhesive systems. United States Patent No.US 20140056949 A1. 2014.

182. L. Roque, J. Alopaeus, C. Reis, P. Rijo, J. Molpeceres, E. Hagesaether, C Reis. Mucoadhesive assessment of different antifungal nanoformulations. Bioinspir Biomim, 13(5), 2018

183. S. Nguyen, M. Hiorth. Advanced drug delivery systems for local treatment of the oral cavity. Ther. Deliv, 6(5), 2015, pp. 595-608

184. E. Verraedt, M. Pendela, E. Adams, J. Hoogmartens, J.A. Martens. Controlled release of chlorhexidine from amorphous microporous silica. J Control Release, 142(1), 2010, pp. 47-52. 
185. J.E. Barry, J.A. Trogolo. Antibiotic toothpaste. World Intellectual Property Organization Patent No. WO2000006208 A1. 2000.

186. S. Khetawat, S. Lodha. Nanotechnology (nanohydroxyapatite crystals): recent advancement in treatment of dentinal hypersensitivity. J Interdiscipl Med Dent Sci, 3, 2015 pp. 181.

187. D. Na, J Faraj, Y. Capan, K. Leung, P. DeLuca. Chewing gum of antimicrobial decapeptide (KSL) as a sustained antiplaque agent: Preformulation study. J Control Release, 107(1), 2005, pp. 122-130 188. L.E. Bromberg, D.K. Buxton, P.M. Friden. Novel periodontal drug delivery system for treatment of periodontitis. J. Control Release. 71(3), 2001, pp. 251-259

189. Grim III, J. Edward. Dentifrice containing encapsulated flavouring. United States Patent No 3957964. 1976

190. W.L. Brown. Denitrifice encapsulation. United States Patent No US4427116A. 1982.

191. C.L. Mackinnon. Encapsulated dentifrice and method of use. United States Patent No 7074390. 2006.

192. J.P. Randall, W.K. Seow, L.J. Walsh. Antibacterial activity of fluoride compounds and herbal toothpastes on Streptococcus mutans: an in vitro study. Aus Dent J, 60(3), 2014, pp. 368-374

193. R.J.M. Lynch, R. Navada, R. Walia.. Low-levels of fluoride in plaque and saliva and their effects on the demineralisation and remineralisation of enamel; role of fluoride toothpastes. Int Dent J, 54(5 Suppl 1), 2004, pp. 304-309.

194. G. Vogel. Oral Fluoride Reservoirs and the Prevention of Dental Caries. Monogr Oral Sci, 22, 2011, pp. 146-157.

195. S.L. Cook, S. Woods, L. Methven, J.K. Parker, V.V. Khutoryanskiy. Mucoadhesive polysaccharides modulate sodium retention, release and taste perception. Food Chem, 240, 2018, pp. 482-489.

196. S. Skovgaards, L.N. Nielsen, M.H. Larsen, R.L. Skov, H. Ingmer, H. Westh. Staphylococcus epidermidis isolated in 1965 are more susceptible to triclosan than current isolates. PLoS One, 8(4), 2013, e62197

197. D.E. Carey, P.J. McNamara. The impact of triclosan on the spread of antibiotic resistance in the environment. Front Microbiol, 5, 2014, pp. 780.

198. S.P. Yazdankhah, A.A. Scheie, E.A. Høiby, B.T. Lunestad, E.Heir, T. Ø. Fotland, K. Naterstad, H. Kruse. Triclosan and antimicrobial resistance in bacteria: an overview. Microb. Drug Resist. 12(2), 2006, pp. 83-90.

199. L.W.B. Olaniyan, N. Mkwetshana, A.I. Okoh. Triclosan in water, implications for human and environmental health. Springerplus, 5(1), 2016, pp. 1639.

200. B. Drury, J. Scott, E.J. Rosi-Marshall, J.J. Kelly.Triclosan exposure increases triclosan resistance and influences taxonomic composition of benthic bacterial communities. Environ. Sci. Technol, 47(15), 2013, pp. 8923-8930.

201. M.F. Yueh, K. Taniguchi, S. Chen, R.M. Evans, B.D. Hammock, M. Karin, R.H. Tukey. The commonly used antimicrobial additive triclosan is a liver tumour promoter. PNAS, 111(48), 2014, pp. 17200-17205.

202. M.T. Dinwiddle, P.D. Terry, J. Chen. Recent Evidence Regarding Triclosan and Cancer Risk. Int. J. Environ Res. Public Health, 11(2), 2014, pp. 2209-2217.

203. S. Lu, M.C. Archer. Fatty acid synthase is a potential molecular target for the chemoprevention of breast cancer. J. Carcinog, 26, 2005, pp. 153-157.

204. D.A. Van Strydonck, D.E. Slot, U. Van der Velden, F. Van der Weijden. Effect of a chlorhexidine mouthrinse on plaque, gingival inflammation and staining in gingivitis patients: a systematic review. DARE, 2012. 
205. N. Eslami, F. Ahrari, O. Rajabi, R. Zamani. The staining effect of different mouthwashes containing nanoparticles on dental enamel. J. Clin. Exp. Dent, 7(4), 2015, pp. 457-461.

206. A. Abbaszadegan, T. Ghahramani, A. Gholami, B. Hemmateenejad, S. Dorostkar, M. Nabavizadeh, H. Sharghi. The Effect of Charge at the Surface of Silver Nanoparticles on Antimicrobial Activity against Gram-Positive and Gram-Negative Bacteria: A Preliminary Study. J. Nanomater, 2015. Article ID 720654

207. I.X. Yin, I.S. Zhao, M.L. Mei, Q. Li, O.Y. Yu, C.H. Chu. Use of Silver Nanomaterials for Caries Prevention: A Concise Review. Int. J. Nanomedicine, 15, 2020 pp. 3181-3191.

208. A. Ebadifar, M. Nomani, S.A. Fatemi. Effect of nano-hydroxyapatite toothpaste on microhardness ofartificial carious lesions created on extracted teeth. J Dent Res Dent Clin Dent Prospects. 11(1), 2017, pp. 14-17.

209. E. Pepla, L.K. Besharat, G. Palalia, G. Tenore, G. Migliau. Nano-hydroxyapatite and its applications in preventive, restorative and regenerative dentistry: a review of literature. Ann Stomatol (Roma). 5(3), 2014, pp. 108-114.

210. A. Mielczarek, J. Michalik. The effect of nano-hydroxyapatite toothpaste on enamel surface remineralization. An in vitro study. Am. J. Dent. 27(6), 2014, pp. 287-290.

211. K. Grocholewicz, G.M. Cichocka, P. Makowiecki, A. Drozdzik, H.E. Chmielewska, A. Dziewulska, M. Tomasik, G. Trybek, J.J. Olszowska. Effect of nano-hydroxyapatite and ozone on approximal initial caries: a randomized clinical trial. Sci Rep. 10, 2020.

212. F. Carrouel, S. Viennot, L. Ottolenghi, C. Gaillard, D. Bourgeois. Nanoparticles as AntiMicrobial, Anti-Inflammatory, and Remineralizing Agents in Oral Care Cosmetics: A Review of the Current Situation. Nanomaterials (Basel), 10(1) 2020, 10(1) pp. 140.

213. R. Pati, R.K. Mehta, S. Mohanty, A. Padhi, M. Sengupta, B. Vaseeharan, C. Goswami, A. Sonawane. Topical application of zinc oxide nanoparticles reduces bacterial skin infection in mice and exhibits antibacterial activity by inducing oxidative stress response and cell membrane disintegration in macrophages. Nanomedicine, 10, 2014, pp. 1195-1208.

214. Y.N. Salvin, J. Asnis, U.O Hafeli, H. Bach. Metal nanoparticles: understanding the mechanisms behind antibacterial activity. J. Nanobiotechnology. 15 (65), 2017.

215. S.A. Saunders. Current practicality of nanotechnology in dentistry. Part 1: Focus on nanocomposite restoratives and biomimetics. Clin. Cosmet. Investig. Dent, 1, 2009, pp. 47-61

216. A. Bhardwaj, A. Bhardwaj, A. Misuriya, S. Maroli, S. Manjula, A.K. Singh. Nanotechnology in dentistry: Present and future. J. Int. Oral Health, 6(1), 2014, pp. 121-126. 